\title{
Goal-oriented processes: Exploring the use of goals in music therapy to support young people with autism spectrum disorder
}

An exegesis submitted to Massey University and Victoria University of

Wellington in partial fulfilment of the requirements for the degree of

Master of Music Therapy

Te Kōkī New Zealand School of Music

Oliver Lowery

2016 


\section{Abstract}

This qualitative research project explored how a student music therapist utilised goaloriented processes to support young people with autism spectrum disorder throughout their course of music therapy. Inductive thematic analysis of selected literature relating to goals in music therapy developed an initial framework of what goal-oriented processes could include. The student music therapist's clinical data (including session notes, monitoring sheets, client reports and reflective journal entries) was then coded through deductive secondary analysis, from which five key themes were formed. The findings indicated that clients' goals were supported by: employing a client-centred philosophical approach; nurturing therapeutic relationships; collaborating with clients and their caregivers; utilising the referral, assessment and review processes; and observing and documenting clients' development. These goal-oriented processes helped to support goals that were meaningful for the clients and their caregivers. Themes were explored in detail using a case vignette to illustrate and provide a context for the findings. Although the context-bound qualitative nature of this research project limits its generalisability, it attempts to provide insight into what goal-oriented processes in music therapy might include, encouraging other music therapists to consider how they utilise goals in their own practice. 


\section{Acknowledgements}

Thank you to -

The providers of the Sir Roy McKenzie Scholarship and Anonymous Music Study Grant, for making it possible for me to perform this research in another city

Dr. Sarah Hoskyns, for your patience, wisdom, guidance, and most of all, time

Dr. Daphne Rickson, for keeping music therapy alive for me

My classmates, for your genius and your madness

The Whānau at my placement facility, for pushing me forward but always having my back

All of the young people and their incredible supporters, for putting your trust in me and letting us explore music together

Mum and Dad, for showing the way, and Daniel, for leading the way

Georgia, for everything

For Lewis 


\section{Ethics Statement}

The Victoria University of Wellington Human Ethics Committee has granted ethical approval for this research project under the generic template approved for NZSM526 Casework and Research (Ethics Approval: 22131 - 15/07/15) 


\section{Table of Contents}

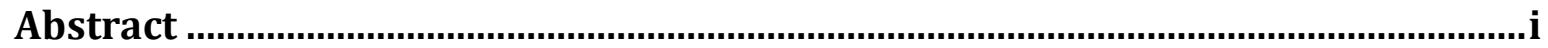

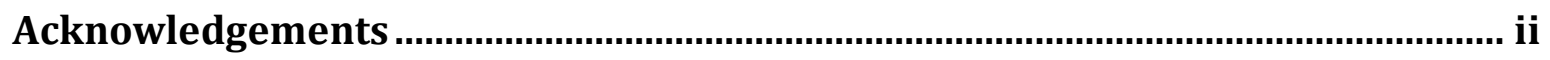

Ethics Statement................................................................................................... iii

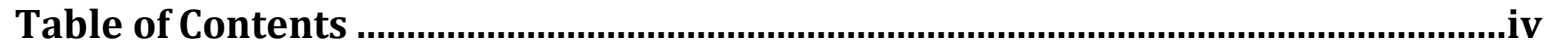

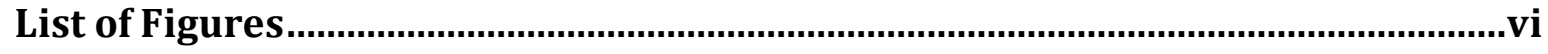

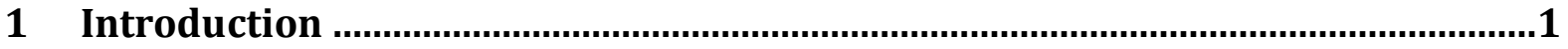

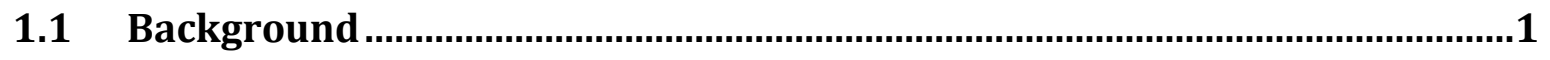

1.2 Setting ..............................................................................................................2

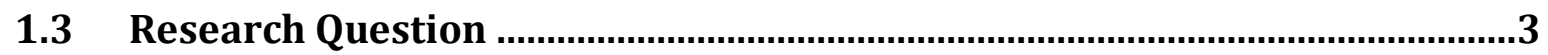

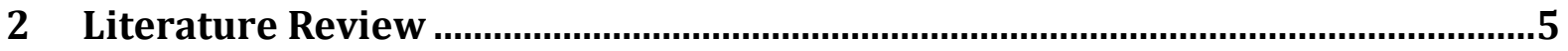

2.1 Music Therapy and Autism Spectrum Disorder .............................................5

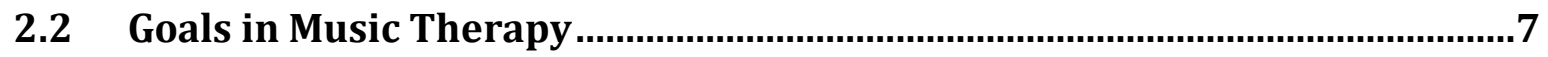

2.3 Music Therapy Approaches ......................................................................... 7

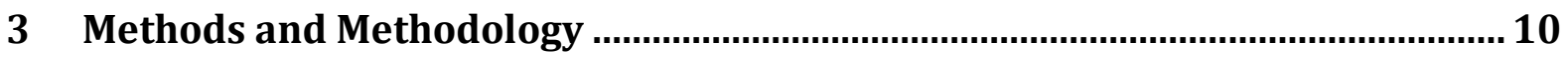

3.1 Theoretical Framework

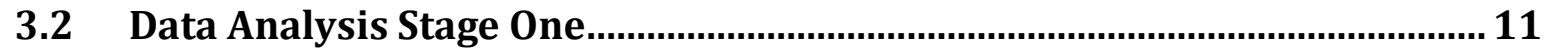

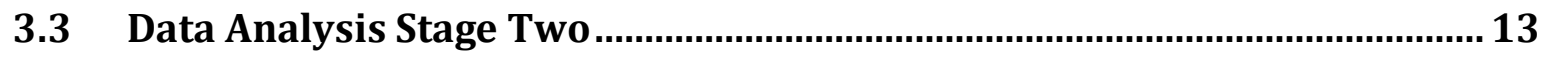

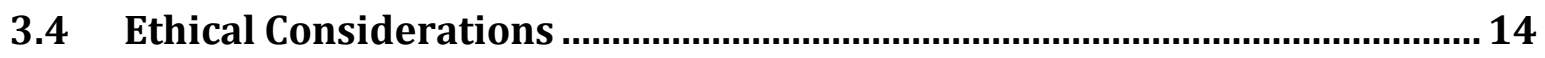

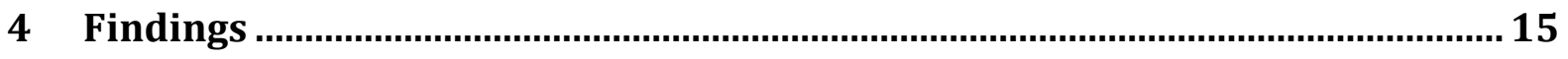

4.1 Stage One: Findings from the Analysis of Selected Literature ................... 15

4.1.1 Philosophies of the facility and the therapist .......................................................15

4.1.2 Formation of a therapeutic relationship ................................................................

4.1.3 Collaboration with clients, caregivers, and other professionals .....................16

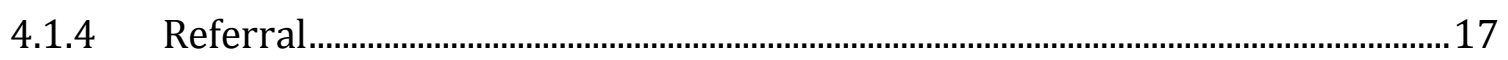

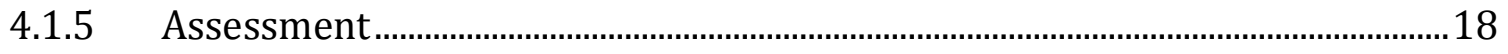

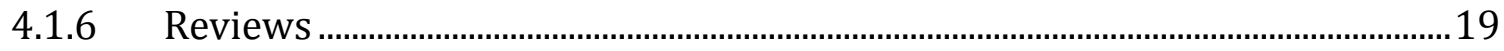

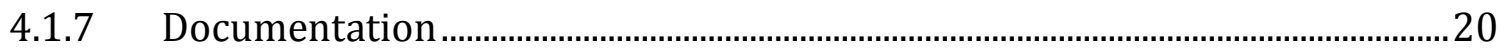

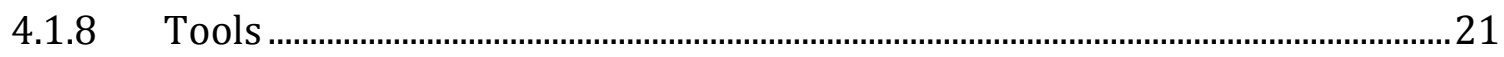

4.2 Stage Two: Findings from the Analysis of Clinical Data .............................. 23

4.2.1 Employing a client-centred philosophical approach ............................................23 
4.2.2 Building, maintaining, and bringing closure to the therapeutic relationship 26

4.2.3 Collaborating with the client and their caregivers.............................................. 30

4.2.4 Utilising the referral, assessment and review processes ...................................33

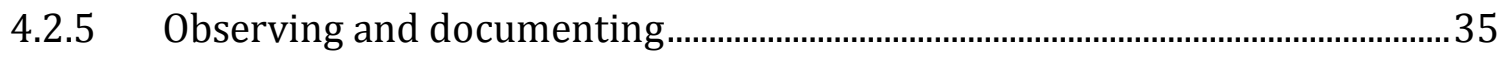

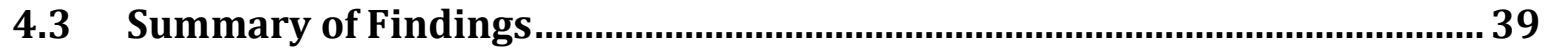

5 Clinical Vignette

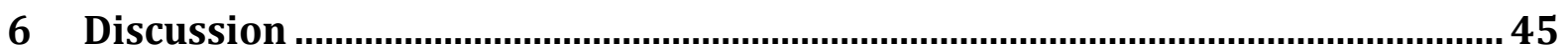

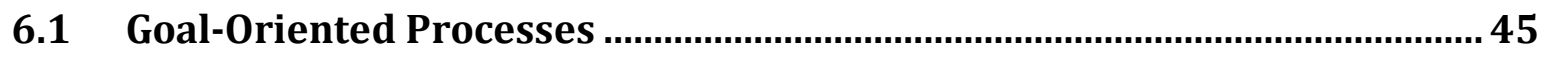

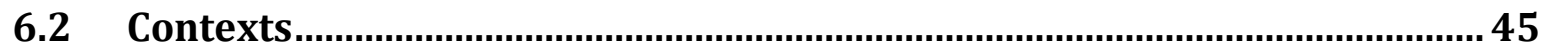

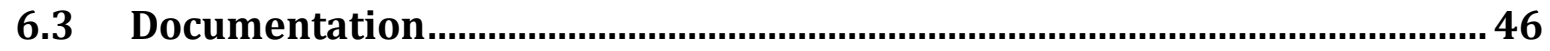

6.4 Autism Spectrum Disorder and Goal-Oriented Processes ........................... 47

6.5 Limitations and Recommendations for Future Research ..........................48

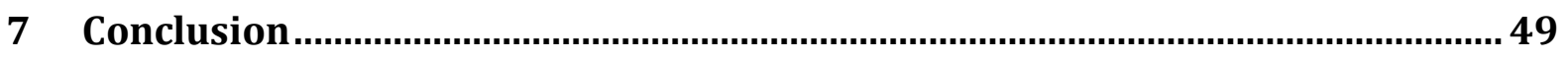

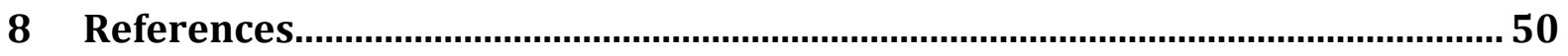

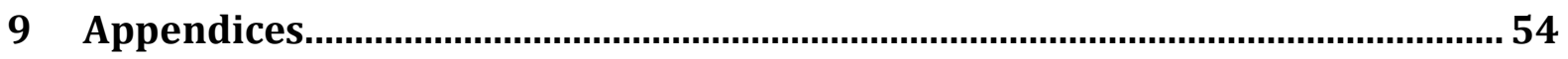

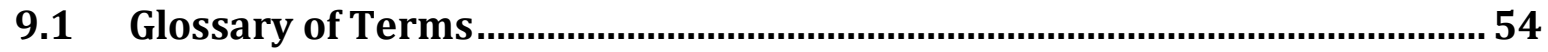

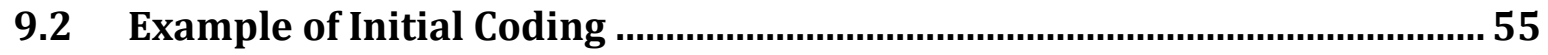

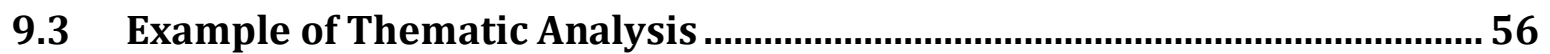

9.4 Example of Goal Monitoring Sheet............................................................ 57

9.5 Letter Seeking Permission to Perform Research at Facility ....................... 58

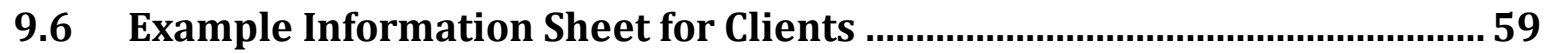

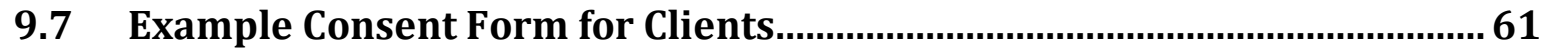

9.8 Example Consent Form for Caregivers …..................................................... 62 


\section{List of Figures}

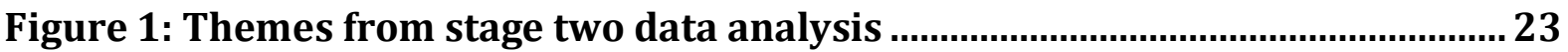

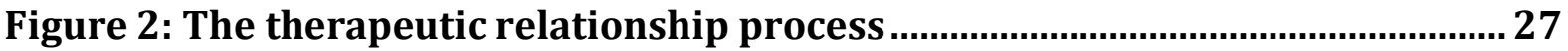

Figure 3: The referral, assessment and review processes ......................................... 34 


\section{Introduction}

This qualitative research project explores my own practices as a student music therapist on placement and I have therefore chosen to write in first person. Although a naturalist philosophy of qualitative research implies an unavoidable interaction between the inquirer and the subject of inquiry, by acknowledging my background and relationship to the research I am able to better distance myself from unduly influencing the research (Wheeler \& Kenny, 2005). Embarking on this research I have employed a constructivist approach, acknowledging that the perception of reality is subjective and based on previous experiences (Edwards, 1999). As a student music therapist with roots in intellectual disability support work, education in jazz guitar performance, and an eclectic music therapy training background, I write from a humanistic perspective that is subjective. I recognise I am influenced both by my personal history and the contexts to which I am bound.

This chapter aims to introduce the subject of inquiry, providing a background and justification for the research before setting out the aims. A literature review will then link relevant research in relation to the research question, before the method of inquiry is outlined in the following chapter. Findings will be presented thematically along with a clinical vignette in order to provide a case example of the findings in practice. The findings will then be discussed, with links made to relevant literature.

\subsection{Background}

This research project was carried out during and following my clinical placement at a facility that delivers music therapy services predominantly to young people with a wide range of special needs. Throughout my practice as a student music therapist I was interested in supporting young people in working towards goals that were meaningful to them. During my 750-hour placement at the facility I became interested in the ways in which goals were not only formulated, but how they were monitored and worked towards. As an evidence-based practice, goals are an important part of the way music therapists work, both in order to promote music therapy as a more widely recognised profession and to adhere to the Code of Ethics for the Practice of Music Therapy in New Zealand (Music Therapy New Zealand, 2012), which explicitly calls for the appropriate use of therapeutic goals. They are a way of remaining resolution-driven in order for 
purposeful change to occur for the clients' benefit. Rather than discussing only how goals were formed, one albeit important part of an entire process, I chose to analyse the whole process of how goals are used, and found the term 'goal-oriented processes' summarised this well.

Often in describing music therapy to the general public, music therapists will refer to the evidence-based and goal-oriented aspects that separate it from music entertainment or other forms of music-use. Although goal-oriented strategies, processes and practices are often referred to in music therapy literature (Berger, 2002; Brunk, 2004; Dileo \& Bradt, 2007; Magee, 1999; Ricciarelli, 2003; Thaut \& Hoemberg, 2014; Thaut, 1984) they are rarely defined or expanded on and it is often left to the reader to interpret a definition. The wide use of the term indicates its importance, however its true meaning is not clearly defined at this time. At a first glance, to be goal-oriented may indicate a philosophy or approach in music therapy, or perhaps attempt to encapsulate goalsetting and goal-monitoring into a tidy phrase. These interpretations are unclear and before a clear definition is formed, there should be more understanding of what goaloriented processes could involve. This research describes some of these processes within a specific context.

\subsection{Setting}

The facility in which the clinical data were created provides music therapy services predominantly to young people with a diverse range of special needs. People who receive music therapy services are referred to as clients and this terminology will be used in the research hereinafter. My placement at the facility involved working alongside a team of music therapists, offering weekly music therapy sessions both onsite and off-site. Clients are often referred to the facility by parents, caregivers, support workers, teachers or health carers. After a one-off consultation involving an exploratory music therapy session and discussion with parents/caregivers, a recommendation of two to three 'focus areas' are set where music therapy may be of benefit. Clients then attend sessions for a period of six to ten weeks known as the 'assessment period'. The assessment period is largely improvisational and allows the music therapist to identify both strengths and challenges for the client (Wigram \& Gold, 2006). After this period, a review takes place in order to decide on a client's suitability for music therapy and to identify individual strengths and needs to specify 
individualised goals for future sessions. Parents and carers are encouraged to take part in the review and consultation process. Music therapy sessions at the facility take place in one of three rooms, which contain a range of instruments including drums, shakers, pianos, guitars, small wind instruments, and a variety of tuned and untuned percussion. Sessions last thirty to forty-five minutes and are recorded via closed-circuit television (CCTV) for analytical reference purposes. Music therapists take notes at the end of each session and these are stored on an internal server and referred to during periodic reviews.

The facility encompasses music therapists with a wide range of theoretical approaches as a result of diverse music therapy backgrounds and training. All music therapists employ individualised approaches that are responsive to client needs, with clientcentred, improvisational approaches commonly used. Approaches are dependent on the therapist and their theoretical orientation, however a holistic approach is strongly valued at the facility. Recent collaborative action research on goal-setting and monitoring processes developed in New Zealand sparked interest in the subject of how goals are used at the facility, with findings providing recommendations for more flexibility in approaches, whilst encouraging universalisation of documentation (Molyneux et al., 2011). It is in this context that I found myself inquisitive about the development of my own practices, with a large focus on how meaningful goals can be developed and monitored using reflexive approaches.

\subsection{Research Question}

How does a student music therapist utilise goal-oriented processes to support young people with autism spectrum disorder?

The purpose of this research was to understand what the goal-oriented processes I utilised in my music therapy practice were, and how I used them to support the young people I worked with, specifically those who have autism spectrum disorder. I chose to investigate my own practices in one way as a form of reflection. As a music therapist early in my career, I had some ideas of what 'kind' of music therapist I was, but this was still a very fresh concept and I was interested in investigating it further. Pavlicevic \& Ansdell (2004) recommend that music therapists consider the philosophies and contexts in which they work and align their approaches accordingly. The facility in 
which I worked advocated a flexible approach that was individualised to the clients' needs, and I was interested in how my practice was positioned within this context and as part of the greater music therapy community. By interrogating my own processes I would have a greater understanding of how I was able to support my clients' goals in ways that were meaningful for them. 


\section{Literature Review}

This brief literature review explores the use of music therapy as an intervention for young people with autism spectrum disorder, as well as bringing together research relevant to the use of goals in music therapy. It does not aim to comprehensively analyse aspects of goal-oriented processes in music therapy as this will be further investigated during the first stage of data analysis, in which selected literature will undergo inductive thematic analysis.

Literature was collected through online library databases including EBSCOhost, Google Scholar, Scopus, and Web of Science, as well as physically within books and journals from Massey University libraries. A number of search strings were used individually and in combination to investigate the many aspects of this research, including "music therapy", "music", "goal-oriented process", "goal”, “aim”, “objective”, “assessment”, "autism", "autism spectrum disorder", "attention deficit hyperactivity disorder", "special needs", and "complex needs". Search strings were expanded as I investigated further.

\subsection{Music Therapy and Autism Spectrum Disorder}

Autism spectrum disorder (hereinafter, ASD), often simply referred to as autism, is a neurodevelopmental disorder diagnosed most commonly in early childhood, though in mild cases can go undiagnosed (Slaughter, 2015). Rather than a singular disorder, it describes a spectrum of conditions ranging from high-functioning autism and Asperger's syndrome to severe disabilities (Dimitriadis \& Smeijsters, 2011). Although there are factors that can increase the risk of ASD, such as familial aggregation (Sandin et al., 2014), there are currently no proven causes or cures (Slaughter, 2015) and treatment focusses on helping individuals to live with their condition. As a spectrum disorder ASD describes a wide range of symptoms, however many individuals experience difficulties with social interaction and communication. According to the DSM-V (American Psychiatric Association, 2013) individuals who have ASD often have trouble: initiating and responding to social interactions; developing, maintaining and understanding relationships; communicating nonverbally with eye contact, gestures and body language; and can become excessively occupied with repetitive behaviours. Individuals can also be oversensitive to environmental conditions such as sounds, lights, and textures. 
A dramatic increase in diagnoses of ASD over the past two decades has led to increased demand for evidence-based practices that address the needs of diagnosed individuals (Lord \& Bishop, 2010). Music therapy has been demonstrated as a useful form of treatment for young people with special needs, and especially effective for young people diagnosed with ASD (Geretsegger, Elefant, Mossler, \& Gold, 2014). ASD has been one of the most widely recognised applications of music therapy, with the early recognition of its efficacy without the need for verbal interaction (Gold, 2011). Its non-confrontational nature means it does not entirely depend on verbal, visual, or physical interaction, thereby allowing clients who have ASD to be less restricted in their communication. Music has been shown to be a stimulus that individuals who have ASD frequently respond well to, with music therapy demonstrated as especially engaging and motivating when compared to other forms of therapy that do not use music (Geretsegger et al., 2014). Through the development of relationships that often require very little verbal or direct physical interaction, music therapy is capable of addressing the social, behavioural, emotional and physical needs of many clients.

An improvisational approach has been widely accepted as a helpful model of music therapy specifically with young people who have developmental needs (Bruscia, 1987; Wigram \& Gold, 2006), though in saying this it is important to note that individuals with ADHD often respond better to highly structured music therapy approaches (Rickson, 2006). Recently, music therapy for people with ASD has been described in two frameworks - the first relationship-based music therapy, and the second neurologic music therapy (Carpente \& LaGasse, 2015). Relationship-based music therapy values the therapeutic relationship in a humanistic manner, relying on coactive musical experiences as the platform for development, whilst the neurologic music therapy framework utilises assessment tools and the application of musical stimuli to address the individual's core needs. The SCERTS Model (Prizant, Wetherby, Rubin, \& Laurent, 2003) is becoming widely used in New Zealand as a way of addressing social communication (SC) and emotional regulation (ER) for young people with ASD through transactional support (TS) methods. It has been demonstrated as an effective way of integrating music therapy into multidisciplinary educational settings using a structured approach (Ayson, 2011; Walworth, 2007). 


\subsection{Goals in Music Therapy}

Music therapy authors often discuss the need for measurable outcomes in music therapy in order for the profession to be more widely accepted amongst mainstream health professionals. Bowens, Scheib, \& Larking (2011) emphasise the need for more evidence-based practice in order for music therapy to be accepted as an effective longterm treatment. Goal setting and monitoring is a way of performing evidence-based practice and is explicitly referred to in the Music Therapy New Zealand (2012) Code of Ethics, which stipulates the appropriate use of therapeutic goals. Goals in music therapy are defined by Cohen \& Gericke (1972) as statements of an end result that bring about a termination or change in treatment, or restoration of a patient's deficits. They are necessary in order for purposeful and effective music therapy to occur in a resolutiondriven manner. Goals in music therapy are often non-musical, instead using music as the vehicle in which goals can be addressed (McFerran \& Shoemark, 2013).

Molyneux et al. (2011) discuss the value of collaborative goal-setting to promote development that is meaningful for clients and their caregivers. They support individualised approaches, focussing on the clients' strengths to work towards the goals. Development can be documented through clinical notes, assessment tools, and audio/video recordings, all of which are helpful when summarising development over a longer period of time. Whether goals are decided by the music therapist, as part of a multidisciplinary team, or in collaboration with the client and their caregivers, it is important for them to be clearly identified in order for purposeful change to occur. Goal-oriented processes indicate an intention for change (or in some cases an intention for continuity) to occur and the role of the music therapy holds that as its core function. It is vital for the client and for the profession that music therapy remains actively resolution-driven, as a universally agreed way of performing ethical practice (American Music Therapy Association, 2013; Australian Music Therapy Association, 2014; Music Therapy New Zealand, 2012).

\subsection{Music Therapy Approaches}

Different music therapy models influence the way in which we think about and involve goal-oriented processes in our practice (Bruscia, 1998). Models of music therapy are often broad and loosely defined, meaning music therapists rarely follow one approach 
and instead employ elements of different philosophies in order to address specific client needs. Wheeler, Shultis, \& Polen (2005) suggest particular ways in which student music therapists might use goals in their practice. Their recommendations appear rather fundamental and direct with little theoretical assignment, however this level of clarity may be considered important for student music therapists as they are unlikely to have a clear philosophical orientation to their practice. Music therapists of all levels of experience can choose to make use of tools to varied extents in their therapeutic approaches. The IMTAP (Individualized Music Therapy Assessment Profile) tool is one of many music therapy tools that support the use of goals in music therapy. It provides guidance from the initial referral process through to the documentation of diagrams that illustrate the young person's development (Baxter et al., 2007).

Music therapists at the facility in which this research takes place employ approaches in line with their own theoretical orientations. These approaches are individualised and responsive to client needs, with a combination of client-centred, music-centred, and improvisational approaches commonly used. Therapists value the creative music therapy philosophy that all people possess an innate musicality and that the therapist attempts to meet the client at his or her 'level' in order to communicate with the 'musical person' (Nordoff \& Robbins, 1977; Wigram, Pedersen, \& Bonde, 2002). Clientcentred music therapy (also referred to as person-centred or child-centred music therapy) is a non-directive form of therapy whereby the client and therapist are coequal in the client's treatment process (Rogers, 1951). Originating in psychotherapy, it allows the client to be empowered in decision-making relating to their own therapy, with the therapist demonstrating 'unconditional positive regard' by following and supporting the client through their exploration process (Wigram et al., 2002). A musiccentred approach involves a therapeutic relationship being built through music and individualised goals are addressed through the music as a vehicle for change (Aigen, 2005a).

A key aspect of humanistic music therapy goals is an aim for self-actualisation, whereby rather than trying to 'fix' a deficit (for example verbal expressive communication), the goals focus on achieving the desired outcome through the clients strengths (which in the described example could be expressive communication through music) (Abrams, 2015; Rogers, 1995). This could be described as a strengths-based approach that values 
the person holistically. However there is a discord between the evidence-based practices that music therapy relies on for professional recognition and the individualised humanistic approaches that cannot be generalised beyond their given contexts (Abrams, 2015). These humanistic philosophical approaches allow for a therapeutic relationship to be formed through the musical interactions facilitated (as opposed to led) by the music therapist, and the goals consequently emerge as a result of, rather than as a precursor to, the musical interactions. 


\section{Methods and Methodology}

\subsection{Theoretical Framework}

In order to understand how I utilised goal-orientated processes in my practice, secondary analysis was used as a methodology to review clinical data and to relate this to key ideas from the literature. The clinical data included clinical notes, client reports, my reflective journal, and selected literature relating to goal-oriented processes in music therapy. Heaton (2004) describes secondary analysis as the analysis of preexisting data in order to answer a new or different research question. It is a suitable research method to answer this question because it reveals themes within the data that may not have been previously apparent as a means to revealing existing and new forms of practice in the field. Methods of analysis included inductive and deductive ${ }^{1}$ coding, whereby portions of the data were assigned words or phrases that summarised their meaning in relation to the question, linking ideas within the data (Saldaña, 2013).

As qualitative research, the relationship between myself and the clinical data must be taken into account (Wheeler \& Kenny, 2005) as it has a strong subjective impact on the findings. However, secondary analysis could be considered as a form of naturalistic inquiry whereby the music therapy intervention remains unchanged and observation is made in a way that has minimal impact on the intervention (Aigen, 2005b), in this case through the review of clinical notes after the music therapy intervention has been completed. This makes it an ethically safer form of research, whereby there are no participants to the research other than myself in reflecting on my own practice. The qualitative and contextual nature of the research means that findings cannot be generalised, but may be meaningful and provoke reflection for other music therapists on their practice in the highlighted areas.

There were two stages to the data analysis in this research, the first analysing selected literature in order to build a data-driven picture of goal-oriented processes within music therapy, and the second analysing my own goal-oriented processes within a

\footnotetext{
${ }^{1}$ Inductive coding involves a 'bottom-up' approach, in which the researcher immerses him or herself in the data in order to identify patterns and themes without trying to fit them within a predefined framework. Deductive coding involves a 'top-down' approach, in which a hypothesis or framework of themes is predefined and the researcher actively searches the data in relation to these. Inductive coding produces rich findings that give a clear image of the data, whilst deductive coding produces findings that relate to the themes defined by the researcher. (Braun \& Clarke, 2006)
} 
selected branch of my practice. For both stages, there were several steps to the thematic analysis beginning with familiarising myself with the data. I then coded the data in relation to how they discussed the use of goals before sorting and synthesising the codes in order to form groups of codes, which indicated a theme. The purpose of having two stages of data analysis was to firstly build a picture of what goal-oriented processes might include in a number of different settings, and secondly to place my approaches (the findings of stage two) within a context of how other music therapists work. The two stages are discussed below.

\subsection{Data Analysis Stage One}

As discussed in the introduction, the term 'goal-oriented processes' was developed in an attempt to encapsulate the many aspects of music therapy that work towards goals, expanding further than just goal-setting and goal-monitoring. Although a summative literature review of current research on the use of goals in music therapy with the discussed population had already taken place, the use of the term 'goal-oriented' remained vague. If a therapist used goals, all of his or her music therapy processes could arguably be interpreted as working towards those goals and therefore be 'goaloriented'. This indicated that I needed to define the term more clearly before I began determining what the goal-oriented processes were in my own data. In order to avoid the naivety of claiming that others had not already described their use of goals, and to better understand what constituted a 'goal-oriented process', I took in a selection of recent literature for analysis. I chose to perform inductive thematic analysis on four diverse pieces of literature from the last ten years, with the aim of identifying common themes of how goals have been used in music therapy. Without any preconceptions of the themes that might emerge, I thoroughly explored the selected literature in order to gain a deeper understanding of how some experienced music therapists have perceived the use of goals, and also how students might be trained to understand their use in the case of one of the sources (see overleaf).

The four pieces of literature were broad in nature, each taking a particular perspective on understanding and building goals in music therapy practice, and provided both local and international insight about a range of approaches. They were similar in that they focussed on, or at least recommended, that their approaches be used with young people 
with developmental disabilities, some focussing on the use of goals for people who have ASD in particular.

- Molyneux et al. (2011) use an action-research methodology to provide insight into music therapy in a local context and touch on two forms of assessment (goal-attainment scaling and narrative assessment), evaluating their suitability in this context. The study also provides insight into factors clients' families may value in music therapy.

- Wheeler, Shultis, \& Polen (2005) describe an approach recommended to student music therapists on clinical placement, which was relevant to my context during the creation of the clinical data.

- Baxter et al. (2007) provide an overview of the functions of the Individual Music Therapy Assessment Profile (IMTAP) tool and how it can be used. The tool is a criterion-based assessment designed for use with young people with developmental disabilities, signifying its potential suitability with the addressed population.

- Walworth (2007) describes the SCERTS model, a multi-disciplinary assessment tool designed for young people who have ASD, and how it could be used in music therapy.

In analysing the literature, I labelled and coded the relevant data using an inductive approach, whereby the data is analysed without any analytic preconceptions (Braun \& Clarke, 2006). I began by reading and re-reading the data in its entirety in order to gain a thorough understanding of the texts as a whole before coding the data. I then grouped the codes, considering their frequency and implied importance ${ }^{2}$, at which point I generated eight themes. These themes provided me with a greater understanding of the some of the factors music therapists often consider when developing and utilising goals. Although their recommendations of therapeutic approach varied, I identified that all of the approaches shared eight common themes that appeared to impact the ways in which goals are used. The themes are presented in the findings section of this exegesis and were taken into consideration during the second stage of data analysis.

\footnotetext{
${ }^{2}$ Qualitative research considers the quality and meaning of data (Wheeler \& Kenny, 2005), but frequency of occurrence of codes will still be considered. Some of the themes I derived were less discussed than others and therefore drew lower frequencies of coding, but were outlined by the authors as being significant or important in goal-use and were therefore included.
} 


\subsection{Data Analysis Stage Two}

The first stage of data analysis provided me with an understanding of some current approaches to goal-oriented processes in music therapy and a number of important themes had emerged. Using these themes as a frame of reference for how goal-oriented processes are used in music therapy, I was able to examine and code my own clinical data in order to draw out and identify the common goal-oriented processes in my own practice. I performed deductive thematic analysis to identify my own goal-oriented processes and view them within the context of other music therapist's approaches. This involved the coding of the clinical data in Microsoft Word (see Appendix 9.2 Example of Initial Coding), which was then transferred into Microsoft Excel for refining and thematic grouping (see Appendix 9.3 Example of Thematic Analysis). All of the themes that emerged in stage one were also found within my data, however there was greater emphasis on certain themes. For this reason, I organised the thoughts and grouped the themes into to five summative finding themes that are presented in the findings section. These themes are later discussed in relation to the original data in order to present an evaluative summary of the goal-oriented processes relevant to music therapy for young people who have ASD.

The secondary analysis of my clinical data involved thematically analysing a pre-defined selection of clinical data in order to reveal a new understanding of the processes that took place. Rather than covering a wide range of cases superficially, I chose to limit the data set to three individual cases and included the entire episodes ${ }^{3}$ of therapy from referral through to closure. The cases were selected solely on their similarities in that they all described young people with ASD who were receiving music therapy treatment onsite at the facility. Although this may be considered a small number of cases, it provided me with an understanding of how goals were used at all stages throughout the therapy process. The three sets of data represented my work with three young people who all had diagnoses of ASD but differed in the severity of the impacts of their disorder as well as in age and socio-cultural backgrounds. My reflective journal was also analysed as a data source, providing personal insight on my thinking and development in relation to goal use.

\footnotetext{
${ }^{3}$ Episode: a group of music therapy sessions taking place over a specific time period.
} 


\subsection{Ethical Considerations}

As a student music therapist I was guided by the Music Therapy New Zealand (2012) Code of ethics for the practice of music therapy in New Zealand, the Victoria University of Wellington (2015) Human ethics policy, and the policies and procedures of the facility in which I was working. Secondary analysis is considered to be a low risk form of research, and this project was given approval under a generic template for the Master of Music Therapy course NZSM 526 Casework and Research by the Victoria University of Wellington Human Ethics Committee (Ethics Approval 22131 - 15/07/15). Data were gathered for clinical purposes exclusively and only analysed following the completion of my clinical placement. Because the focus of the research was on my practice, consent was not required from clients nor their caregivers, other than for those discussed in the clinical vignette. Informed consent was only sought after the completion of therapy, reducing the risk of the Hawthorne effect ${ }^{4}$. Informed consent (see Appendix 9.6 Example Information Sheet for Clients) was also gained from the facility for the use of clinical data.

The individuals that the analysed clinical data relates to have been given pseudonyms to protect their confidentiality. They are referred to as 'clients' and 'caregivers' in the collective, in accordance with the policies and procedures of the facility at which the music therapy took place. As music therapy is still relatively uncommon as a practice in New Zealand, the young person and caregiver discussed in the clinical vignette were advised of the risk of identification through association with my work, so that they could make an informed choice about the work being described in more detail. Although the research was considered low risk, ethical mindfulness was exercised throughout.

\footnotetext{
${ }^{4}$ The Hawthorne effect describes the impact of subjects' awareness of their being observed on their behaviour (McCarney et al., 2007).
} 


\section{Findings}

\subsection{Stage One: Findings from the Analysis of Selected Literature}

These themes are the findings from an inductive thematic analysis of four diverse pieces of recent literature that discuss the use of goals in music therapy. Eight patterns emerged from the data, identifying some of the themes ${ }^{5}$ that explain how goal-oriented processes have been used within a range of approaches.

\subsubsection{Philosophies of the facility and the therapist}

Thematic analysis of the literature found that the philosophy of the facility or setting that the therapist works within has significant impacts on how goals are used. These can be as a result of funding agreements, cultural principles, foundations based on a particular model, or central values set by the facility. These influence the frequency of reviews, length of the episode of therapy, style of documentation, use of tools, and disposition to collaborate with others both inside and outside the therapy room.

It is also important to note that within facilities, individual therapists possess their own philosophies and these too affect the way goals are used. As dynamic beings, they carry their own values and beliefs, and although therapists work hard to self-monitor and remain open-minded, it is inevitable (and in many ways important) that their backgrounds and experiences will in some way affect how the clients and their needs are viewed. Individual therapists also make decisions on what they feel safe handling, both physically and therapeutically, and this will impact at some level on the approach in which goals are created, worked towards, and measured.

\subsubsection{Formation of a therapeutic relationship}

A client-centred approach supports the premise that because goals originate from within the therapy setting, a trusting client-therapist relationship with musical interresponsiveness is the only way in which meaningful goals can emerge (Rogers, 1951). This makes the formation of this relationship the first step in the therapeutic process, beginning as early as possible with both clients and their caregivers. Particularly when

\footnotetext{
${ }^{5}$ The themes are not necessarily represented in all of the pieces of literature, but emerged as important in at least one piece of literature. Unless only relating to one piece of literature, themes have not been individually attributed, as the aim is not to understand 'who says what' but instead to understand collectively what themes may be considered.
} 
working with people who have ASD, it can be important to create a comfortable, nonthreatening environment in which clients feel safe to express themselves creatively and make steps towards forming a therapeutic relationship. Ensuring consistency in session settings and routines can help to decrease anxiety on the clients' part, promoting creative expression from which more accurate strengths and needs can emerge. Some music therapists claim that the goal during the assessment period is to be tending to the therapeutic relationship, because that is what provides the opportunity for the best goals for that individual to emerge. Some music therapists place less emphasis on the therapeutic relationship and focus on the treatment of physical diagnoses, though this is more common in mediatised 'treatment with music' approaches to music therapy.

\subsubsection{Collaboration with clients, caregivers, and other professionals}

Collaboration can take place at many points in the therapy process and its use is closely linked to the philosophical approach of the music therapy. In many other professions, goals often relate to aims of achieving to a curriculum or standard, however some music therapists prefer to collaborate with the client and their caregivers in order to attain their hopes rather than attempting to meet those of society (Wheeler et al., 2005). Goals that are given or formed by the client or their caregivers can be more meaningful to them than those formed solely by the therapist. Being involved in the goal creation process can also be empowering for the client and enrich the therapeutic relationship, furthermore improving the goals efficacy. A positive relationship (including collaboration) with clients' caregivers has been shown to improve goal achievement greatly across many disciplines (New Zealand Education Gazette, 2009). Caregivers can also be included during the sessions in order to help achieve goals. This may involve providing comfort for clients, helping clients physically while the therapist focusses on the music, or being present in the room when the focus of the goal is on the relationship between the client and the caregiver. Involving caregivers can also help the client to generalise their learnt skills beyond the music therapy environment, and into their home and the community.

Some tools recommend collaboration with families and caregivers early in the goalsetting process, seeking input during the client referral and assessment stages. Both the Goal Attainment Scaling (GAS) and the IMTAP tools are used to capture and document 
the clients' development in a way that is clear for the clients' families to understand, which provides further opportunities for collaboration ${ }^{6}$.

Referrals can sometimes come from within multidisciplinary teams, often with less opportunity for further information gathering from the initial referrer. In this case, music therapists sometimes share the goals previously set by other professionals, so long as they feel they are appropriate and can be addressed through the use of music therapy (for example, working on a fine motor control goal set by a physiotherapist, or creating a song that helps with daily routines in the school setting). Whilst the goal may be the same, there would be different music therapy methods to achieve the goal. In some settings a multidisciplinary tool can be used to provide a platform for collaboration between professions, creating a unified approach towards a goal. Collaboration with other professionals can even be as small as discussing a detail with another professional involved in the clients' care in order to gather further information. It is important for music therapists to be aware of other professionals working with a client and to understand roles they can play in helping the client reach their goals.

Whilst is important to take into account the advice and desires expressed during the collaborative process, the music therapist is the professional in their area of work and has their own valid opinions on how goals should be used. Families may not be familiar with music therapy techniques and educating them can be important in revealing the most appropriate goals as well as ensuring they understand and can support work towards these goals where needed.

\subsubsection{Referral}

As the referrer often approaches music therapy to address a particular need, desire, hope, problem or issue that they wish to address, the initial referral provides the first insight into possible clients goals. Meetings and interviews with the referrer are common, and can be performed by the music therapist or in some cases a senior music therapist. The referrer may provide background information that includes previous or concurrent treatments, which can indicate techniques that have previously been effective or ineffective and the appropriateness of potential goals (e.g. ensuring a goal does not run counter to a separate goal being worked towards in another setting).

${ }^{6}$ Documentation and tools are closely linked to collaboration and are discussed in further depth in their own sections 
Background information on clients' musical abilities as well as physical and intellectual capacities are relevant in informing the appropriateness of goals and techniques used in working towards them. During the referral process, the therapist identifies any time constraints that the work may be restricted to, as this can impact both the extent to which goals are set and whether certain goals are addressed at all (e.g. not addressing goals that would require a lot of work when only a small time frame is given, in order to provide purposeful therapy and avoid potentially worsening an issue). In a short term case, setting a more easily achievable goal may be seen as a step in the right direction rather than looking too far ahead. In some situations a formal assessment process may not be appropriate and goals can be set during the referral process based on the information available at hand and ongoing informal assessment.

The referral often informs the music therapist of the client's clinical diagnosis, which some therapists may then use to give a sense of some of the client's characteristics by considering common generalisations linked to that diagnosis. These could be attributes such as a difficulty performing specific tasks, or positive responses to certain therapeutic methods. Although these are presumptuous and are unlikely to be accurate for every person with a particular diagnosis, they are generally informative and prompt to therapist to seek further information from the referrer or employ particular approaches in the therapy sessions. This practice is utilised to varying degrees across music therapy, however all of the literature shared the view that knowledge and understanding of the potential strengths and weaknesses associated with a particular diagnosis is important in setting and working towards appropriate goals. Some music therapists prescribe goals from a list that links particular deficits with pre-determined objectives (Walworth, 2007), however this appears less common.

\subsubsection{Assessment}

All of the pieces of literature analysed support an assessment period in music therapy as an important way of considering goals. The assessment can inform the music therapist of the clients needs as well as their strengths. It also informs them of potential treatment techniques that may be appropriate, and can help with refining individualised goals.

Some music therapists recommend assessing abilities of clients who have ASD in clearly pre-defined areas, whilst others choose to assess what a child is able to do and choose 
to build on these strengths. The former approach may involve choosing a selection of domains to assess based on those highlighted in the referral. Specific activities can be used to assess each domain, which helps with planning the content of assessment sessions. The scores or levels of achievement against these domains can be used to determine the extent to which a goal is set, or the appropriateness of a goal altogether. The latter approach is a more client-centred, less structured approach in which a range of activities are explored with the client, providing opportunities for clients to demonstrate their abilities in a number of situations. In either approach, assessment of the clients' musicality can be assessed in order to help with choosing future session content from which goals can be set and then worked towards.

When setting goals based on the needs of the client, music therapists can differentiate between a focus area and a goal. The focus area gives the area in need of attention (e.g. improved communication skills) and is usually decided before the assessment begins, whilst the goal gives a more specific aim within that focus area (e.g. use of verbal communication to request an instrument) and can be decided during or after the assessment (Wheeler et al., 2005). Some music therapists go a step further to add objectives, which give an exact measurement of achievement (e.g. use of verbal communication to request an instrument at least once per session). Not all music therapists utilise this approach with some choosing not to define specific targets, arguing that this can instil a sense of failure with the client and his or her caregivers, when in fact it may have been the goal that was simply inappropriate.

\subsubsection{Reviews}

Reviewing goals and client development is another opportunity for collaboration with clients' caregivers. Reviews often involve discussion with caregivers and/or other professionals involved in the clients' care, with the purpose of reflecting on progress and assessing the suitability of goals. Some music therapists recommend video recording7 sessions for the purpose of reflection by the therapist as well as the ability to share and discuss the content of sessions with caregivers and other professionals involved in the clients' care. Some tools provide forms of documentation that outline areas for discussion, including achievements, difficulties, techniques used, notice of changes outside of music therapy, and feedback from caregivers and other

\footnotetext{
${ }^{7}$ Further discussion on the use of video-recording can be found under the Documentation theme.
} 
professionals. It is considered important to discuss both intended and unintended outcomes from the sessions, as these can generate ideas for the way in which goals are worked towards.

Frequency of reviews can be influenced by the setting, with external structures such as Individual Education Plans (IEPs) requiring them at an established minimum regularity. When the review frequency is not constrained by the setting, music therapists can review goals when it is felt necessary - this could be when a goal is achieved, when a goal is taking longer than expected, or at the request of the caregivers. Some music therapists advise a timeframe in which progress should be observed (and if it is not then the intervention should be changed), whilst others claim that time-frames are client-specific and should be individualised. It is a shared view that if goals are not being achieved in a reasonable amount of time (defined in collaboration with the therapist and caregivers), then a review should take place to re-evaluate expectations or discuss a new approach to the goal, or the goal itself. In this case, the clients' development determines the frequency of review.

In client-centred music therapy goals are not always addressed in every session as the client may use the music therapy space for a purpose that is not part of their goals at the time. This is often considered acceptable, however if it were to continue for an extended number of sessions it may be worth reviewing the appropriateness of the goals chosen for that particular point in time. A client who repeatedly seeks to use the musical space for a particular purpose may be an indication that their goals should focus on that area.

\subsubsection{Documentation}

All of the analysed literature emphasised the significance of the relationship between documentation and goal-use, and stressed that clear documentation is important in communicating and collaborating with everyone involved in the music therapy process. There were however distinct differences in the style of documentation between different approaches in music therapy. There appeared to be a demand for measurable goals, yet an appreciation for the usefulness of descriptive documentation. Funding often relies on evidence-based practice, and documentation that is generalisable appears to be common in the medical world. However the world of education has seen change in a move to descriptive narrative style documentation that can be 
individualised to the child. Music therapy often bridges many arenas and hence styles and uses of documentation can vary greatly.

Some music therapists utilise tools that provide a means of capturing and documenting development in a way that can be easily understood for non-music therapists, using visual diagrams to show progress and summary forms to outline client strengths and needs (Baxter et al., 2007). These tools can use computer software to log session data, which can then be put into graphs to visually represent change over time. A profile of a client's strengths and challenges can be formed, indicating areas of growth and areas in need of further development. Tools can also be used in planning sessions, as specific focus areas can be linked to musical activities or strategies that aim to facilitate skill development in that area. It is recommended that music therapists refer to their clients performance in an ongoing way between sessions in order to help with planning effective future sessions.

Other music therapists advocate a descriptive narrative style of documentation rather than using the quantitative style, which they argue may not portray the true nature of the work (Molyneux et al., 2011). Through narrative description, judgements can be explained and justified and give greater understanding to the music therapy process. A clients development can be described from the perspective of those working with him or her, assessing the clients development in relation to their own abilities rather than comparing them to others. A descriptive narrative style of documentation can be especially useful in the assessment period, as the early nature of the sessions may mean that focus areas are not yet well defined, and gathering data regardless of apparent relevance can help later when the focus of the therapy is better defined.

Finally, some music therapists advocate for both descriptive documentation and the use of tools, used in conjunction to support each other. The use of video and audio recording was not mentioned frequently but was strongly supported, both for the purposes of recall for the therapist (e.g. to log quantitative measurements or add detail to session notes) and as evidence to support statements of development or challenges in reviews.

\subsubsection{Tools}

Facilities and music therapists may employ the use of tools to assist their practice and support the use of goals with a systematic approach. Tools can be used as a complete 
'package' that guides the process from start to finish, or as part of the process to provide support where required. When using goals, tools are used most commonly to document and illustrate clients' progress in specific developmental domains. They often provide a way of quantifying achievements in a way that is clear and easy to understand for everyone involved in the therapy process. During reviews, the visual aspect of diagrams and charts helps to clearly convey trends in a clients progress, and some tools provide summary sheets that help to facilitate structured conversation during meetings with caregivers.

Computer software can be used to log scores, and automate diagrams and summary sheets (Baxter et al., 2007). Some tools provide suggested developmental domains to be assessed and include standardised charts with clearly defined objectives to assist the music therapist in scoring clients' performances. Scoring may be based on how many times the client performs the objective, how long the client performs the objective for, or how consistent the client is in performing the objective. A low score in a domain indicates a need for work in that area, and goals and objectives are formed in relation to those scores. The tool may also provide suggested strategies that can be used to promote development in specific domains. Tools can be used to help the music therapist to reflect on a clients progress and plan sessions with certain domains in mind from which specific songs, instruments and activities can be attributed and used.

Both internationally and locally there is no standard tool used in music therapy, nor a standard tool used with people who have ASD. Some music therapists advocate for the use of specific tools as a means of unifying approaches to support young people who have ASD, whilst others argue that the individualised nature of their approach to music therapy makes a standardised tool limiting and inappropriate. It is important to note that in the New Zealand context a holistic view of healthcare is supported by the Māori concept of hauora, whereby four forms of well-being (physical, mental \& emotional, social, and spiritual) are equally valued. It is argued that many tools are not able to support this holistic view, but does not rule them out from being used as a part of a complete process. Some music therapists advocate the use of both tools and more descriptive forms of assessment. 


\subsection{Stage Two: Findings from the Analysis of Clinical Data}

During the analysis of my own clinical data five themes were formed, which provided better understanding on how I personally utilised goal-oriented processes to support my clients' development. The themes related back to the findings in Stage One of my data analysis, however some of the original themes held greater significance in my own data and were expanded upon, whilst others revealed different approaches, and some were seldom addressed. Many of the themes are strongly linked, and although displaying the themes as completely separate concepts would be misrepresentative, I have organised the findings into groups in order to help with understanding the data in relation to the research question.

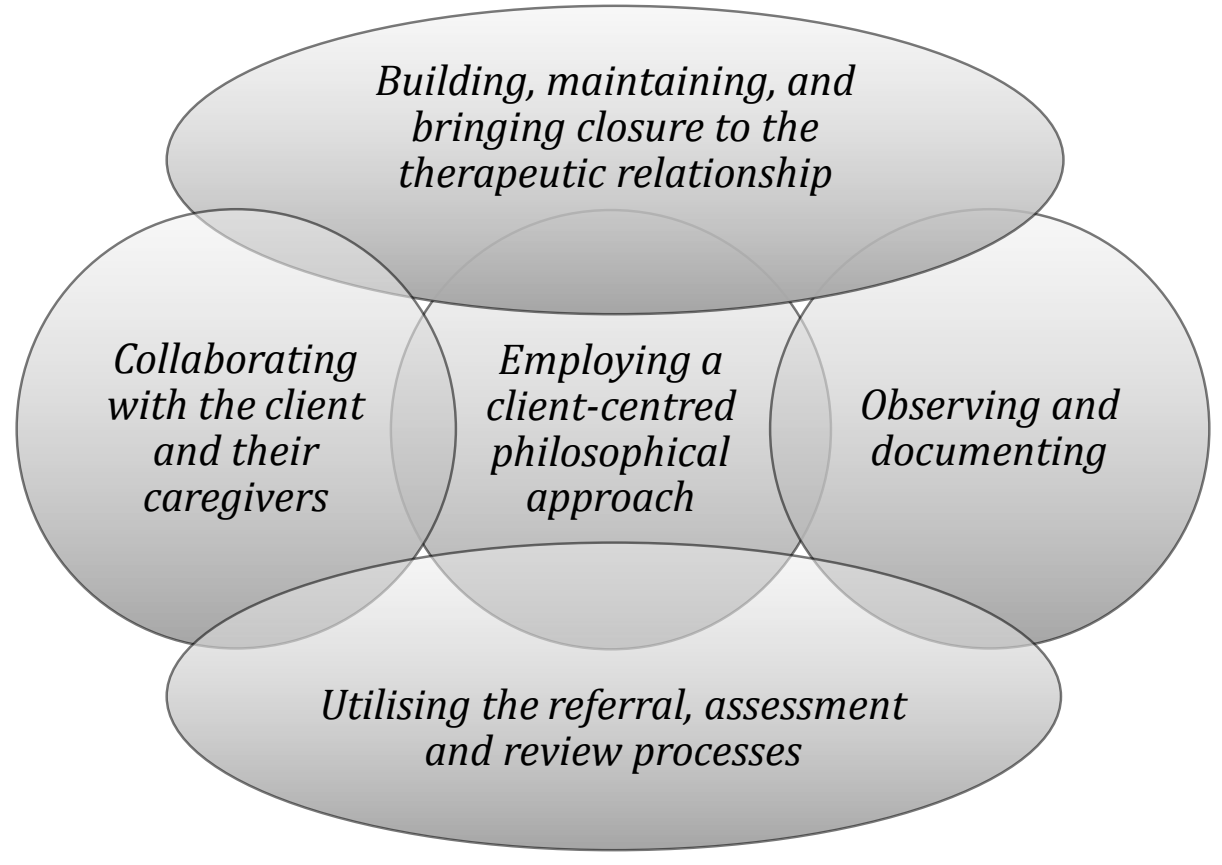

Figure 1: Themes from stage two data analysis

\subsubsection{Employing a client-centred philosophical approach}

It was clear throughout the data that my music therapy practice is underpinned by a client-centred philosophical approach. I valued established therapeutic relationships as the platform from which goals could emerge and be worked towards based on the clients' own strengths. This was critical to the way in which I worked to form individualised goals that were meaningful for the client and their caregivers. It involved forming and nurturing therapeutic relationships; encouraging clients to explore a range of situations in order to 
reveal their strengths; focussing on their strengths rather than their deficits; supporting and enhancing clients' input on sessions; and working to best meet the needs of the client. My approach was influenced by my personal background, my training and supervision, the facility's philosophies, and the client population that I worked with.

At the start of clients' therapy I used an open, semi-structured session style that allowed the client to explore a wide range of situations in which they could showcase their strengths and challenges. Although caregivers had often communicated areas in which they might like the clients to develop, whilst these were noted I focussed on interacting and attuning to the client, whilst observing their reactions to different situations. This allowed me to identify the contexts in which clients engaged most effectively. Strengths were not considered to be activities that clients were 'good at', but activities that they appeared to enjoy or engage well in. Sometimes I removed instruments from the room that prevented clients from exploring (such as instruments they perseverated ${ }^{8}$ on), before reintroducing them once I felt they had had ample opportunity to explore other instruments and activities.

It was difficult to predict the emotional state that each client would be in when they attended their sessions, and it was therefore impossible to plan exactly what would happen in a session. Instead I prepared a number of strategies that could be used where the opportunity arose, acknowledging that the context of the clients' emotional states greatly influenced the session content. As clients became more comfortable in the musical space, they often initiated musical expressions without prompt. I focussed on validating and supporting their expressions by repeating them back, enhancing them, and including them prominently in the improvised music. An open, improvisational structure to sessions allowed for the client to direct session content without the demand for high levels of communication.

As we played on the autoharp, he began verbalising many different foods names off the top of his head. I improvised a song where I incorporated foods he was listing into the song, which he seemed to respond to by continuing to list foods. (Dylan's Clinical Notes, Session 6, 18.05.15)

\footnotetext{
8 Perseveration is the demonstration of repetitive behaviour such as flapping or twirling, often referred to as being 'stuck' performing a behaviour.
} 
We did not work on the individualised goals that had been set during review meetings every session, instead allowing space for clients to address their needs at the time. When clients continuously demonstrated a need in a particular area that had not been initially included in their goals, we reconsidered their set goals and altered them to better fit their new needs. Although it was recommended by the facility that review meetings take place every six months, there was flexibility allowed in their frequency to individualise the music therapy process as needed.

For clients with a higher functioning level of communication, I often asked what they wanted to work on during sessions, allowing them to use the music therapy space for their needs as defined by themselves. This ranged from suggesting or offering choice from a range of activities, or leaving it completely up to the clients to express what they wanted to do. When openly discussing what they wanted to address seemed inappropriate, improvisations, lyric-writing and song sharing were useful strategies in identifying potential areas in a non-confrontational way. Activities such as song-writing were useful as they allowed me to initiate the process and then gradually withdraw my creative input, encouraging the clients to take over the creative process while I facilitated and provided guidance where needed. I often took on clients' suggestions and enhanced them in a way that supported their goals. Conversations often directed session content, as they were an effective way of identifying the clients' emotional state and choosing appropriate activities to address their needs.

He opened up about an incident that happened at school today where he and his friend had had an argument because of a disagreement over X. He felt that he wasn't ready to forgive them and was quite worked up about it, describing $X$. He improvised a very dark and muddy piece of music with me that ended suddenly without much resolution, prompting more discussion about the situation. (Hayden's Clinical Notes, Session 13, 16.06.15)

Sometimes when clients arrived early for sessions, I encouraged them to help choose the instruments to put in the room, allowing them to have greater input on their therapy content. Part of having increased client input on session content and ultimately how they worked towards their goals was that it promoted independence whilst enhancing their awareness of their own development, allowing them to better generalise their skills. In order to promote this further, in some situations I encouraged 
clients to attend review meetings with their caregivers so that we could openly discuss what their goals might be and how we might work towards them.

The client-centred approach extended into how goal development was observed and monitored. Instead of using standardised assessment tools and scales, I monitored clients' development in relation to their own abilities, individualising the monitoring process. In doing this I did not always document measurements of length or frequency of behaviours, instead predominantly focussing on whether there had been a sense of improvement. This allowed for consideration of the context of clients' behaviour, acknowledging the influence of their emotional states in a way that did not have an unnecessary negatively impact. I acknowledged clients' awareness of their own development equally if not more than my own observations, as it encouraged clients to be in control of their development. To do this, I often openly encouraged clients with higher functioning communication abilities to reflect on their challenges and what helps them, sometimes sharing my own observations of to how they had previously progressed. In some cases, goals were focussed on clients' abilities to recognise their own development.

He played very accurately and grinned powerfully after accomplishing the quick chord sequences in the tricky parts of the song. Afterwards he repeatedly said "Wow" and when I asked if it was a good wow or bad wow, he replied "I'm shocked" "in a good way - I didn't think I would be able to do that". It was good to see him impressed by his own achievements and I linked this back to the practice he had done. (Hayden's Clinical Notes, Session 13, 16.06.15)

As the therapeutic process came to a close, I refocused clients' goals onto nurturing and bringing closure to the therapeutic relationship, once again valuing it as the platform from which we were able to identify and work towards their goals.

\subsubsection{Building, maintaining, and bringing closure to the therapeutic relationship}

I observed in the data that in employing a client-centred philosophical approach, I strongly valued the fostering of the therapeutic relationship in relation to the use of goals throughout the music therapy process. Efforts were made to form, maintain, monitor and bring closure to a meaningful client-therapist relationship from which goals could be realised and worked towards. This bears strong links to a client-centred philosophical approach, where goals emerge and are addressed through the therapeutic relationship. In 
this sense, the core goal at the start of therapy is to form the therapeutic relationship so that meaningful goals can emerge. The data revealed three stages to the therapeutic relationship, portrayed in the diagram below (also showing some of the codes that lead to the finding).
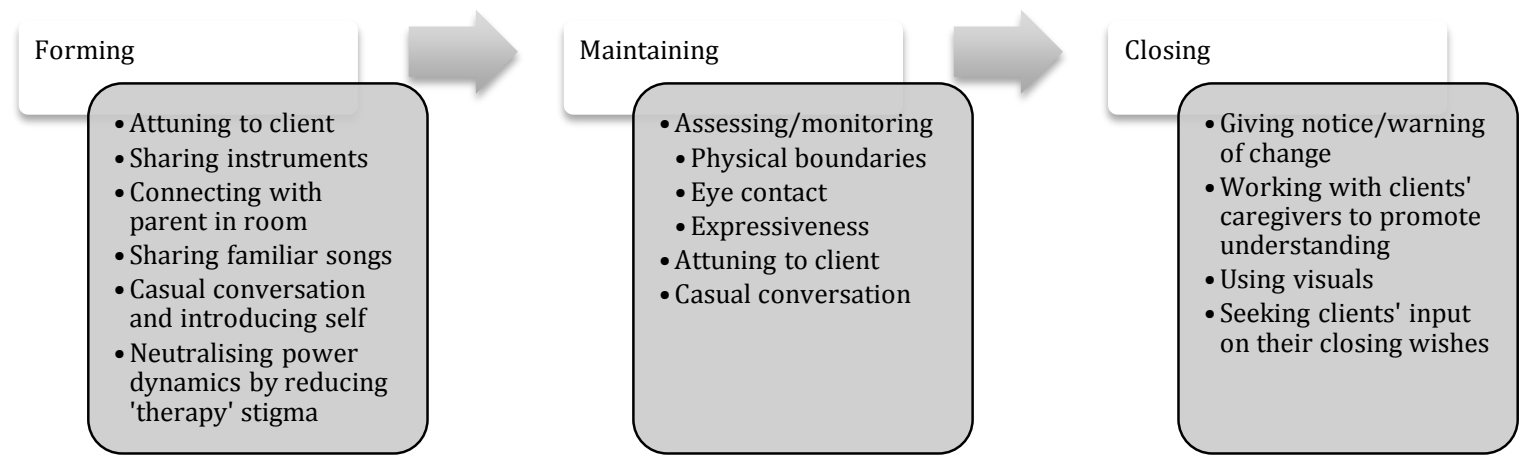

Figure 2: The therapeutic relationship process

In my observations of the first stage of therapy, in my practice forming the therapeutic relationship with the client was always the primary goal. A meaningful client-therapist relationship leads to greater engagement and in doing so reveals the most meaningful and appropriate goals for that client whilst also empowering them to work towards those goals in a client-led manner. In some cases, I utilised the secure attachments of clients to their caregivers in order to build trust, as demonstrated by attachment theory ${ }^{9}$. The client was able to explore the room and interact with me relatively comfortably in their caregivers presence. Some caregivers also helped me to understand what the client was saying or meaning, allowing me to address their communications more suitably.

Finn has his own phrases for expressing his wants and needs, and it has been helpful having his mother in the session to translate these for me to help me to understand him in order to strengthen our relationship. He spent time both near his mother and exploring the room. (Finn's Clinical Notes, Session 7,06.05.15)

I engaged both the caregiver and the client in joint musical activities in order to promote our relationship. Playing music together was the most evident technique used

\footnotetext{
${ }^{9}$ First developed by John Bowlby and Mary Ainsworth, attachment theory describes how infants and young children rely on physiological and psychological secure attachments to their primary caregivers in order to regulate emotion, explore physical and social environments, and form positive relationships later in life (Bretherton, 1992).
} 
to build trust, firstly on separate instruments where I would try to engage in the music being made by the client (matching and complementing harmony, rhythm or pitch), then later moving on to share instruments that were played together.

As Finn's ability to trust me in our therapeutic relationship built, he allowed us to share instruments such as the ocean drum, the gathering drum, and sometimes the piano. These were an effective way to connect with Finn without using other methods that may have been too confrontational. (Finn's Assessment Report, 14.08.15)

Playing and discussing familiar songs provided a platform for connection with all of my clients, both when initiated by myself and when initiated by the client (in which case I would join and support them musically). In many cases I would begin the sharing process, after which the client may have gained confidence to 'reveal' their musical self, allowing connections to be made. In some cases it became apparent that the stigma of 'therapy' and the client-therapist power dynamic was impacting our ability to progress. This lead me to focus on working towards a more neutral power balance. I did this by encouraging the client to teach me their songs, and this appeared to boost his confidence.

Hayden taught me the chords for 'Let It Go' (including the verse) and sang while playing along (I only played but didn't sing). He built in confidence, to the point where later in the session he sang solo on 'Thinking Out Loud' while I played the piano part (his suggestion - I had also never played it on piano which may have comforted him). (Hayden's Clinical Notes, Session 18, 25.08.15)

Conversation also provided a means to connect with clients, as a quick 'catch-up' at the start of each session offered opportunities for the client to convey current happenings in their life and connect over current events, as well as allowing me to understand some of what was figuratively being brought into each session.

Maintaining the therapeutic relationship involves similar techniques, but the aim is for the therapeutic relationship to have already been established and for new individualised goals to be the primary focus. I was able to monitor therapeutic relationships by observing clients' body language, such as their eye contact and comfort in sharing personal space, as well as the way they engaged and expressed themselves musically. For verbally communicative clients I also considered the sharing of personal content in conversations to be an indicator of a well-established therapeutic 
relationship. Sometimes when a client became upset for reasons inside or outside of the session, it became important that the focus of the moment be attuning to them, reassuring trust in the therapeutic relationship, and putting aside their specified goals.

Dylan entered the room early, hitting his mother and crying. I suggested we begin early in order to try to calm Dylan as soon as possible. As I entered he was still hitting his mother, but he calmed and made strong eye contact with me as I began the hello song. As he curled up in his mothers arms, he appeared to relax and listen to a very slow and quiet hello song. (Dylan's Clinical Notes, Session 12, 22.07.15)

This allowed for the restoration of trust in working with me and the environment he was in, and the client was then able to continue to engage in the therapeutic relationship that allows for development towards goals.

The findings of stage one focussed on the processes involved in the formation of the therapeutic relationship, however the findings of stage two showed emphasis on bringing closure to the therapeutic relationship in order to support my clients. Similarly to the early stages of the therapy process, the primary goal in the final stages focusses on nurturing the therapeutic relationship, with the specified goals becoming secondary. The use of visuals helped me to convey the ending of an episode to clients with communication difficulties. This often included counting down numbers with images of us or the room and was presented to the client at the start and end of the final 3-5 sessions. Where clients were to continue music therapy with another therapist, I introduced them to the new therapist before our final session to help prepare them for the transition. I worked collaboratively with the caregivers of clients to try to help them to understand that we were finishing, as sometimes parents were able to communicate this in a way that could improve the clients' understanding.

Afterwards, I showed Dylan the visual again to remind him and showed that we now had two sessions left. (Dylan's Mother) asked Dylan to say "(New Therapist's Name)", which he did while looking at her picture. (Dylan's Clinical Notes, Session 17, 07.09.15)

For clients who had stronger communication abilities, we discussed the ending of therapy openly and could then use the musical space to explore feelings around this (for example, having an improvisation based on the theme of endings). I encouraged and allowed clients to use the final sessions as they wished, allowing them to finish on their own terms. 


\subsubsection{Collaborating with the client and their caregivers}

The data revealed a significant emphasis on collaboration with clients and their caregivers as a way that I was able to formulate and monitor meaningful goals for them. I openly communicated with clients and their families in a way that both informed them and helped to inform me at multiple points through the therapy process. Collaborating with the client involved encouraging the client: to decide on the content of sessions; to recognise their own development and how they had achieved it; to monitor and report on their own development; and to discuss and have input on what their goals are and how they might achieve them. Collaborating with caregivers involved: utilising their observations both inside and outside of sessions; acknowledging their interpretations of client behaviours and expressions; modelling social engagement; exercising client-caregiver relationships; and identifying effective strategies, favourite songs or instruments, and perceived strengths and challenges of the client. It also allowed me to observe from a third-person perspective as I supported the clients interactions with their caregiver, and to share the observations made through a therapeutic lens that the caregivers may not have otherwise noticed. I collaborated with clients and caregivers frequently during reviews and regarded their views as paramount to how I applied the use of goals.

One strength of a well-established line of communication is the ability to have another set of eyes monitoring a client's development. I recognised the significance of clientreported and caregiver-reported development, both in sessions and at home or in the community. For higher functioning, verbally communicative clients, there was often regular open discussion about how the client felt they were progressing - sometimes with the goal itself and sometimes with an activity that aimed to develop and assess a skill.

He later reflected on his own development in being able to both focus on what he was doing, whilst also moving with the people he is playing with. (Hayden's Goal Monitoring Sheet, Session 22, 22.09.15)

Encouraging the client to reflect on their development appeared to be beneficial for their self-esteem as they became more aware of their achievements. Continued reflection also meant that they were able to realise how they had reached their 
achievements and subsequently how to generalise their skills across other situations to continue their development.

We practiced one particularly difficult part on repeat in order to get better at it and he reflected that it was definitely helpful to repeat things rather than stop when it was difficult. (Hayden's Clinical Notes, Session 12, 02.06.15)

The clinical data included discussions with caregivers who reported development outside of the sessions. Although it is impossible to attribute change directly to the music therapy with so many variables at play, most caregivers claimed that they felt the reported development was as a result of the sessions. They reported development as well as challenges in relation to the clients goals, which helped me to recognise how close the client was to their goal.

(Hayden's Mother) has noticed a change in Hayden's interactions around home, with him demonstrating more patience and social awareness with friends and family, which she attributes to his music therapy sessions. She also noted that his attention span with tasks has increased and he has been spending more time focussed on the practice and learning of his new musical interests than previously. (Hayden's Assessment Report, 12.05.15)

In some cases, one caregiver also joined the client and I in the room during sessions, whilst another caregiver occasionally observed via a closed-circuit audio-video link. For clients who experienced significant communication difficulties, I valued the presence of a caregiver who knew the client well and was able to explain what they were most likely trying to express. This reduced frustration on the client's part and allowed me to respond appropriately in a way that more accurately addressed their needs. Caregivers were often able to tell me the names of songs that clients referenced, and identify the instruments, songs and activities that they felt the client enjoyed the most. Having this extra observation also meant that demonstrations of development were more likely to be noticed and documented. Equally, I was able to convey observations I had made to the caregivers that they may not have noticed, especially through the thinking of a therapeutic lens.

I observed and shared with Dylan's mother that he had spent far more time exploring and far less time 'attached' to her during this session, and she shared that she has noticed him becoming more relaxed in sessions. (Dylan's Clinical Notes, Session 4, 06.05.15) 
It appeared beneficial for caregivers to witness the clients' development first hand, as their support and willingness to engage in the music therapy process increased the more demonstrated evidence they saw of progress.

Early in the development of the therapeutic relationship, clients often seemed more likely to interact confidently when their caregiver joined in on musical activities such as group drumming or turn taking with instruments. In these cases, the caregiver's presence was very important in having the client engage and thus build confidence in the music therapy environment and with me. Occasionally I partially removed myself from interactions and provided simple musical support to facilitate the caregiver and client's interactions. This provided an opportunity to observe from a third-person perspective, gathering information on a client's abilities and how they interacted, whilst providing the caregiver and client with interactions that the caregivers often commented on as 'special moments'. Caregivers were also valuable in praising clients when they demonstrated a desired behaviour, providing familiar positive encouragement that often resulted in continued motivation to engage.

There were often events where I would have been unsure and potentially self-blaming about the reasons for a client's behaviour during a session, however it is understandable that there are endless other variables that impact a client's mood and behaviour. A caregiver was often the most likely person to be aware of these factors, and could also provide warning for future happenings that may impact the way or the direction we work, especially in relation to goals. For example, a client may have had a poor sleep the night before or been excitable the past week at school, giving me an opportunity to adjust for this by structuring the session accordingly. Providing warning for significant future changes may alter the direction of goals, often focussing the new or revised goal on preparing the client to cope and manage with that change.

(On the topic of starting school) we discussed the idea that new routines and having to fit to the structures of others may cause some stress for him. We agreed that music therapy could be a good opportunity to provide some continuity for him through this time of change, while also providing a space for creative expression. (Finn's Assessment Report, 14.08.15)

This concept carried through the review meetings, as I strongly valued caregivers' input on choosing the goals that they felt were best for the client. Their presence in sessions 
also gave them a better idea of what goals were most appropriate for the music therapy environment.

Sometimes I used the caregivers' presence quite specifically to work towards goals that focussed on the client's social interactions. In one case, I gradually decreased the caregiver's presence in sessions over time (by having them attend for beginnings and endings but leave for increasing periods of time through the core of the sessions) in order to promote the client's independence.

Dylan's mother was out of the session for the first 10 minutes and he seemed fine with her not being there. I will gradually increase the time she spends out of sessions over the next few weeks. (Dylan's Clinical Notes, Session 8, 03.06.15)

In a separate case, I encouraged the caregiver to be a part of the sessions as much as possible in order to collaboratively model interactions of social engagement, which helped the client to engage with people more appropriately. Both situations utilised the caregiver's presence in different ways, and the decision came back to the individual goals of the client. In my reflective journal on 27.06.15, I expressed that I had felt an expectation for the caregiver to eventually not be present in the sessions, however upon reflection felt that unless their absence helped work towards a goal or was negatively impacting the session, there was no reason that I could find to not have them there. I considered the caregivers' cherishing the sessions to be beneficial as it provided them with positive experiences, which increased their enthusiasm and support for the music therapy process whilst also enriching the clients' experiences.

\subsubsection{Utilising the referral, assessment and review processes}

As discussed in the findings of stage one, the referral provides the first indication of the potential goals and strategies that can be used during music therapy. The assessment then helps to gather further information to define the goals in greater detail, a process that is discussed and established during the review. This three-step process forms part of the policies and procedures for the facility where I worked, however it also allows for a great amount of flexibility and the application of an individualised approach. As shown in more detail overleaf, it involves collaboration with caregivers and the client at multiple points throughout the process, as well as documentation and observation of specific details for the purposes of developing the most appropriate goals for the client. 

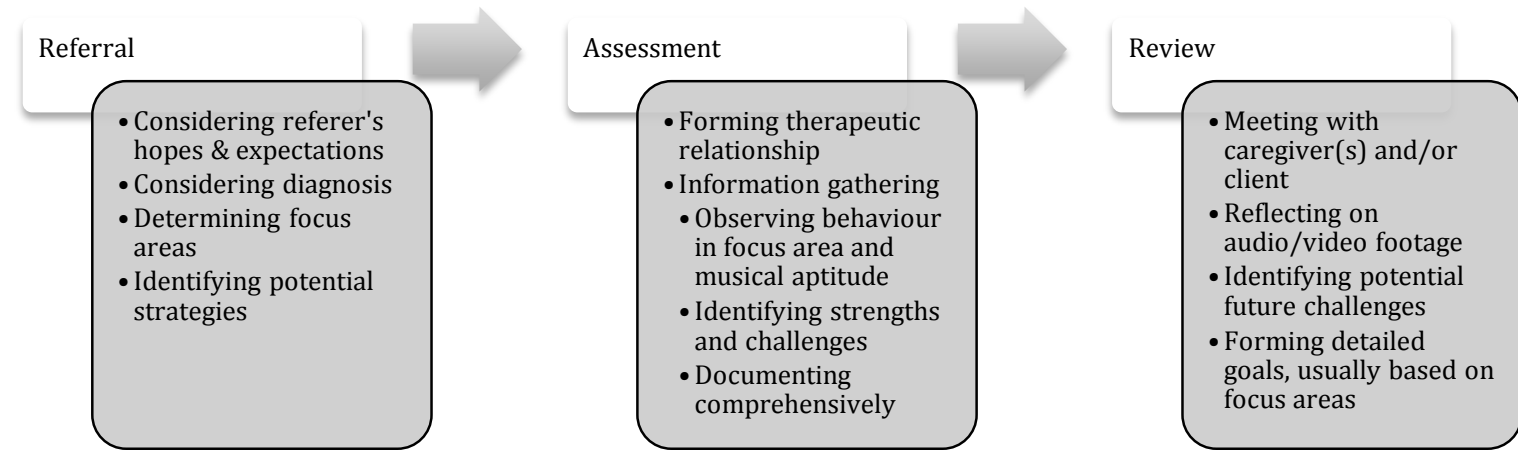

Figure 3: The referral, assessment and review processes

All of the clinical data that were analysed referred to work with clients who had diagnoses of Autism Spectrum Disorder (ASD), although some clients also had cooccurring diagnoses of Attention Deficit Hyperactivity Disorder (ADHD) and Global Developmental Delays (GDDs). Although I considered some common focus areas linked to these diagnoses, the majority of the information leading to goal development came from the client and their caregivers. Often the referrer provided hopes and expectations for what the client might be able to achieve and I was able to consider the suitability of music therapy to address it.

She felt that music therapy may assist with helping to increase Hayden's focussed attention and concentration span. (Hayden's Assessment Report, 12.05.15)

Drawing on my training and past experience, I considered potential strategies to address these focus areas. This helped prepare me for the assessment process, however I retained an open mind as to the goals that may emerge from the therapeutic relationship. The assessment period bore two main roles - the formation of the therapeutic relationship (as previously discussed) and an opportunity for information gathering. The focus areas determined in the referral (of which there were two to three) were noted and documented as I began working interactively with the client. As the assessment process began, I observed clients' behaviours in the determined focus areas as well as assessing their musical aptitude. I explored the clients' reactions to different activities and strategies, and also identified difficulties and challenges that arose. Their response to music therapy was documented in detail in order to collect as much information as possible, with the thinking that we did not know at the time what could be important to refer back to in the future. Through comprehensive interaction and 
observation during the assessment period, I was able to develop an unofficial form of baseline for the expectation of behaviours, allowing me to recognise improvement later.

The assessment period was recommended to be approximately ten sessions in length by the facility with allowance for flexibility where appropriate. My assessment periods were between seven and thirteen sessions. In shorter term work, it was possible for the assessment period to be shortened to suit. Some clients took longer than others to settle into the musical space and therefore required more time for their goals to emerge. At the end of the assessment process I held a review meeting with the caregivers and sometimes included the client, to discuss our collective reflections on the assessment sessions. Reviewing video footage helped us recall and reflect on parts of the assessment sessions, allowing for discussion based on visual evidence. The clients caregivers were also able to identify potential future challenges that they hoped to prepare the client for and these often became part of the agreed goals.

(On the topic of starting school) we discussed the idea that new routines and having to fit to the structures of others may cause some stress for him. We agreed that music therapy could be a good opportunity to provide some continuity for him through this time of change, while also providing a space for creative expression. (Finn's Assessment Report, 14.08.15) ${ }^{10}$

Taking into account the original focus areas, we formed more detailed achievable goals for the client. We also discussed the most effective strategies and techniques, and noted these as potential ways to work towards the goals.

\subsubsection{Observing and documenting}

Purposeful observation and documentation was a key finding that defined how I was able to implement meaningful goals for the client and their caregivers, and then monitor and adapt the goals and the strategies used as required. It was important throughout the therapy process and involved: identifying and utilising strengths and challenges; considering appropriate methods for development; planning sessions; taking into account clients' emotional states; individualising objectives of achievement; utilising audio-video recording; acknowledging client and caregiver-reported development; and using descriptive documentation in order to provide a context for development that was clear and detailed for everyone involved.

10 This data was also quoted in 4.2.3 Collaborating with the client and their caregivers, demonstrating the integrated nature of these themes 
Throughout the music therapy process I observed clients' behaviours and interactions with the musical environment in order to inform how I was able to support them best to choose and work towards agreed goals. By identifying the clients' strengths and challenges I was able decide on the most potentially engaging strategies and activities in order to plan and prepare for sessions. Documenting also became part of the planning process as alongside the strengths and challenges from sessions, I would note ideas for future sessions, some of which were suggested by clients or caregivers. The identification of effective strategies evolved in relation to the generalised goals of the assessment period and the individualised goals of later sessions, in the sense that I initially identified strategies that helped to engage and develop the therapeutic relationship, and then later focussed more on identifying strategies that helped clients to work towards their defined goals. Strengths were not limited to things that the client was 'good at', instead focussing on the things they enjoyed and were therefore most likely to engage with.

When I identified challenges, I responded in two different ways depending on the goals at the time. In some cases I identified a challenge and attempted to avoid it or remove it from the room in order to allow the client to explore more freely without becoming 'stuck' on that challenge. This was common early in the assessment period, as I wanted to observe and interact with the client in as many situations as possible, allowing them to best demonstrate their abilities. In other cases, often after the assessment period when individual goals had been set, I decided that the challenge related to the goals and focus areas, identifying a need to work through that challenge.

I tried reintroducing the beaters into our session, which I had removed early in the episode because Dylan had become 'stuck' flapping them in a sensory stimulative way. By removing them, Dylan had been more explorative of the instruments, but I felt that it may be useful to reintroduce them in a way that gives them purpose. (Dylan's Clinical Notes, Session 11, 01.07.15)

This strategy required intense monitoring, as my approach changed in accordance with the clients' development and it was important to be aware when challenging them was appropriate and when the therapeutic relationship required nurturing. I varied the level of structure based on clients' confidence in the room, often beginning with very open, unstructured sessions in order to promote exploration, and later moving to a semistructured model in order to focus development on specific focus areas. In some cases it 
became clear from monitoring that the time of the session in relation to other daily routines was negatively influencing the clients' ability to engage effectively. By being aware of this and altering the session times and/or environments, the clients were able to engage more effectively in order to work towards their goals. I became increasingly aware of clients' emotional state of during the course of my developing practice. It had significant impacts on pursuing their established goals. When clients were confident to engage appropriately, we usually worked towards their individualised goals, however when clients were upset or uncooperative I focussed on the goal of nurturing the therapeutic relationship. ${ }^{11}$

(Dylan's Mother) and Dylan both appeared stressed as they came in, with Dylan holding to the door frame crying and saying "noo!" about coming into the room. (Dylan's Mother) commented that it had been a crazy afternoon. ...I placed the guitar down and moved to the piano where I began playing gentle arpeggiated chords in time with his mothers swaying. As I began to play 'Twinkle Twinkle Little Star', Dylan began to stop crying and eventually slowed his breathing. As I introduced swells of chords he turned his head and watched the piano in a gaze. (Dylan's Clinical Notes, Session 16, 31.08.15)

In documenting clients' development, I also took into account their emotional state in relation to their achievements. A client may have been excited to engage and explore a lot of instruments on one day demonstrating development. However on another day they may initially appear resistant to engaging and exploration, but by the end of the session engage briefly on an instrument, demonstrating an achievement in relation to the difficult initial context. I valued the narrative style of documentation in describing how clients developed as it allowed for inclusion of these types of factors.

Rich, descriptive documentation was especially important in early sessions, as it gathered comprehensive data that were useful to recall once the goals had become clearer. Achievements and challenges were documented with their context, allowing me to recreate environments that supported development. After the assessment and review processes, clients' clinical notes predominantly focussed on documenting data that related to the goals. Once the individualised goals had been formed, I created goal

\footnotetext{
11 This is not to say that goals could not be worked towards when a client was upset or uncooperative, rather that the client's behaviour should be considered a form of communication, and in doing so forcing the therapist to reflect on the appropriateness of the current goals. Often 'managing self' and 'reducing challenging behaviour' were goals themselves.
} 
monitoring sheets ${ }^{12}$ which allowed me to briefly document examples of development. The goal monitoring sheets were created by the facility to be used in a similar nature to a observational tool but with far more flexibility. These were useful in overviewing the client's development as they did not use the narrative form, but still had an approach of comparing the client to their own development over time (rather than comparing their development against the measurements of a standardised tool). This was easy to understand and summarise. It was important to document an informal 'baseline' of expected behaviour in order to compare future developments against. Although I sometimes documented the frequency, length and other measured data of behaviours from sessions, more often than not development was documented in relation to previous behaviours, indicating the perceived level of change in descriptive terms. The clients' clinical notes were used to document anecdotal evidence of development that focussed on the client's strengths, often providing simple examples of demonstrated behaviours.

Finn verbalised "guitar" very clearly (no longer "di titar") while pointing to it. (Finn's Clinical Notes, Session 20, 23.09.15)

The narrative style of documentation was also used in reports shared with caregivers as it conveyed a sense of development with clarity and detail. Good understanding of clients' development allowed caregivers to support them appropriately, both in their music therapy and at home. As discussed previously, client-reported development was also strongly valued, as their awareness of their achievements and challenges often lead to increased willingness to work towards their goals.

Although the focus of the sessions was on non-musical goals, a semi-music-centred approach was sometimes beneficial in identifying and monitoring development. I was able to promote clients' confidence through mastery of musical skills, which encouraged further development. Development of a particular musical skill was used as an indication of development towards a goal, especially when the goal related to concentration and persistence (for example, a client being able to play through a full song or self-correct mistakes without frustration is an indication of development).

He played the ukulele with ease on this song, accurately correcting minor mistakes with no signs of frustration. (Hayden's Clinical Notes, Session 11, 26.05.15)

12 An example of a goal-monitoring sheet is included in the appendices 
The use of audio/video recording (which was part of the policies and procedures of the facility) also helped with recalling both historic and recent sessions, allowing me to focus on 'being' in the musical space rather than trying to memorise what had happened during the sessions. It also came into use during review sessions, providing visual evidence as a platform for discussion with clients' caregivers, and they expressed value in being able to see evidence of the clients' development.

\subsection{Summary of Findings}

The findings suggest that the philosophies and approaches utilised by the therapist (or indeed the facility in which they work) have a significant impact on the ways in which goal-oriented processes are used. The themes that emerged during the literature analysis indicated a number of approaches that all define and work towards goals in ways that are influenced by their context. In the analysis of my clinical data, I found that I emphasised a client-centred approach that valued the therapeutic relationship, doing so without the use of standardised tools. The therapeutic relationship provided a platform from which goals could be identified, negotiated and worked towards in ways that were genuine and meaningful for the client. In my experience, both clients with high-functioning autism and clients who had more complicated forms of ASD were able to be a part of their goal-forming process through the methods that I employed. It is important to stress however that my approach was relevant to the settings and people I was engaging with, emphasising the context-bound nature of goal-oriented processes.

Although the presentation of my findings may at times read as a description of how I work generally, I found that the holistic nature of how I utilised goal-oriented processes was a function in almost all of the aspects of my practice, necessitating their inclusion. 


\section{Clinical Vignette}

During my clinical placement I worked with a wide range of young people with varied goals. I have chosen to describe my work with Hayden, as his was a case that encompassed many of the themes that emerged through the course of this research. At the time of my clinical placement, Hayden was a 14-year-old boy who lived at home with his mother and attended a mainstream high school. He had been diagnosed with attention deficit hyperactivity disorder (ADHD) several years earlier and had recently been given a diagnosis of autism spectrum disorder (ASD) prior to being referred to the facility for music therapy. He was referred by his mother, Sophie, as they were both coming to terms with his recent diagnosis. She had heard about music therapy through autism support networks and initially hoped that it might help Hayden to increase his focussed attention and concentration span and support his interest in learning musical instruments.

As per the facility's policies and procedures, a senior Registered Music Therapist (RMTh) facilitated an initial exploratory music therapy session with Hayden, and also held a consultative meeting with both Sophie and Hayden in order to gather further information. The RMTh observed that Hayden had presented as a highly motivated individual with a strong interest in music and the ability to follow verbal instructions, and recommended music therapy to address three focus areas as listed below.

- Creative self-expression

- Musical experimentation and skill development

- Developing attention and concentration skills

It was also indicated that the therapeutic relationship may also provide a safe, supportive space for Hayden to explore his feelings about his recent diagnosis of ASD.

Hayden attended weekly individual music therapy sessions with me, totalling twentytwo sessions (including seven assessment sessions) over seven months. Before we began our sessions I had some time to examine his case file, including his referral and consultation notes. It was clear that although some focus areas had been recommended, I would not immediately be able to identify specific goals or strategies to work with based on his diagnosis, hopes, or brief interactions with the RMTh. I kept an open mind going into the assessment sessions, hoping that I would be able to identify his strengths 
and that the goals would emerge through the exploration of a number of different situations.

Initially he was curious about what music therapy entailed and asked many questions. He was very interested in my idea that music could potentially be an expressive outlet rather than just an educational one, as he had initially thought music therapy might have been more like the music subject at his school. Sometimes he would bring music theory questions that I would answer, and then we would incorporate his new knowledge into an improvisation or familiar song. He appeared to enjoy taking turns copying rhythms on the large conga drums and discussing the use of different chords to create different moods in improvisations. We found connections through familiar songs that he and I both shared with each other, mostly from the 'Top 40' genre, but including some older 'classics' too. Playing even a small part of a song that he had asked for without preparation, created a genuine connection and he gradually became less hesitant to engage musically. Our therapeutic relationship was building, and I was beginning to see Hayden's strengths and how we could work towards his focus areas.

As our sessions progressed, Hayden became very interested in the ukulele, to the extent of acquiring one for his home use. His musical skills on a wide range of instruments developed quickly and we began exploring more expressive ways of using music including thematic improvisations and lyrical analysis, both of which Hayden reflectively articulated on during discussions. I introduced lyric analysis as a way of thinking about music expressively, which Hayden seemed to naturally engage in, and later he began analysing song lyrics that stood out to him without any prompting. Our sessions often involved a reasonably high amount of conversation in which Hayden was increasingly open and sharing of his experiences and feelings. Hayden began to reflect on his musical achievements in a positive way and responded well to constructive feedback. As his confidence developed he became more explorative and tried new instruments such as the piano as a way of changing the sound of familiar songs.

Hayden, Sophie and I met for a review meeting after Hayden's seventh session, as I felt that Hayden and I had developed a good platform for development and were ready to identify some specific individualised goals. Hayden expressed an enjoyment in attending music therapy sessions, specifically with drumming activities and playing 
popular songs. He stated that his interest in the ukulele had extended to learning songs at home and taking part in playing as a part of a group in his music class at school. He expressed a desire to continue learning instruments and spoke about his musical future. Sophie shared that she had noticed a change in Hayden's interactions around home, with him demonstrating more patience and social awareness with friends and family, which she attributed to his music therapy sessions. She also noted that his attention span with tasks had increased and he had been spending more time focussed on the practice and learning of his new musical interests than previously.

In considering Hayden's enjoyment learning an instrument and his expressed desire to keep doing so, I decided that music therapy could be a space to learn the skills needed to take instrumental lessons, including focus and attention as well as being able to respond appropriately to constructive feedback. The act of learning an instrument had assisted him in developing skills in listening, concentration and persistence. It had also provided him with a means for creative expression. All of these skills could be generalised into non-therapeutic settings, and it seemed appropriate as this should be the end-goal. Based on our discussion at the review meeting we developed some short term goals founded on the initial three focus areas along with some strategies in which we could work towards them, as shown below.

\begin{tabular}{|c|c|c|}
\hline Long-term focus & Short-term goal & Strategies \\
\hline Creative Self-expression & $\begin{array}{l}\text { - Continue to explore a wide range of } \\
\text { instruments } \\
\text { - Recognise and utilise the musical space } \\
\text { as a means for expression }\end{array}$ & $\begin{array}{ll}\text { - } & \text { Song writing } \\
\text { - } & \text { Free improvisation } \\
\text { - } & \text { Thematic improvisation } \\
\text { - } & \text { Lyric analysis }\end{array}$ \\
\hline $\begin{array}{l}\text { Musical Experimentation } \\
\text { and Skill Development }\end{array}$ & $\begin{array}{l}\text { - Continue to develop skills on a range of } \\
\text { instruments } \\
\text { - } \quad \text { Continue to try out new instruments } \\
\text { - } \quad \text { Acknowledge and respond appropriately } \\
\text { to constructive feedback }\end{array}$ & $\begin{array}{l}\text { - Learning and practicing } \\
\text { popular songs } \\
\text { - Transferring known songs } \\
\text { across different instruments } \\
\text { - Aural rhythmic and harmonic } \\
\text { activities }\end{array}$ \\
\hline $\begin{array}{l}\text { Developing Attention } \\
\text { and Concentration Skills }\end{array}$ & $\begin{array}{l}\text { - Increase persistence with activities, most } \\
\text { importantly in moments of difficulty } \\
\text { - Improve listening and interaction with } \\
\text { activities involving others }\end{array}$ & $\begin{array}{l}\text { - } \quad \text { Learning and practicing } \\
\text { popular songs } \\
\text { - } \quad \text { Copy rhythm activities } \\
\text { - } \quad \text { Drumming activities } \\
\end{array}$ \\
\hline $\begin{array}{c}\text { Notes: } \\
\text { - Potential to cons }\end{array}$ & 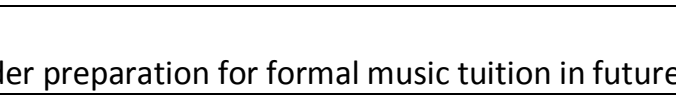 & \\
\hline
\end{tabular}

Following the review meeting, Hayden became more proactive in developing his musical skills and transferring them across different platforms. He often came to 
sessions with new techniques learnt at home from the internet, and would be excited to show them to me before applying them together to familiar songs. Although he had always been confident in asking questions, through open discussions he was able to develop his skills in identifying areas that he found difficult and addressing areas needing attention.

We also continued to analyse the lyrics of popular songs, and Hayden was able to link connections to his own feelings. As this progressed it became less of a planned activity within sessions, instead seeming to naturally come up when talking about songs in general. Improvisation became a useful means for addressing subjects in a non-verbal way.

In the latter half of the episode, Hayden and I spent a lot of time on song-writing as a creative outlet for expression and skill development. I initially provided guidance on the choices we might make in writing a song (e.g. how fast, what rhythms, what chords, what the words were about), but Hayden was quick to take over the creative process. He wrote lyrics for two songs, eventually combining them to create one piece which, on his suggestion, we recorded and I sent to him as an mp3 file. He seemed proud of his song, updating Sophie about it after sessions. The recording of the song took place in the last three sessions as we prepared to finish our therapy together. I had asked Hayden how he would like to spend the time and he had asked if we could record his song, as well as play through the familiar songs we had played in the past. I felt that it was a fitting way to bring closure to our therapeutic relationship, whilst also providing him with a positive memento that was evidence of his development.

Music was a useful platform for increasing Hayden's attention and focus on task-based activities. The client-centred approach was useful in Hayden's case as it empowered him to be in control of his own therapy. By encouraging him to be in control of his therapy, he became increasingly self-driven and was able to extend skills acquired within music therapy into the home setting where spent a lot of time learning and practicing new songs and skills. The use of conversation as a therapeutic tool seemed developmentally appropriate and helped to identify meaningful goals in an authentic environment. Incorporating musical skills such as keeping a constant rhythm and repetition as a form of practice and learning were a useful way of increasing persistence and self discipline, 
and it was hoped that Hayden would then be able to transfer these skills across other areas of his life. As a fourteen year old, the generalisation of his skills was important and resourcing him with developmentally appropriate tools for his development was essential. The music therapy relationship gave Hayden the valuable experience of being able to express himself in a safe relationship and environment. Hayden achieved a great deal in the sessions, most notably, building an interactive therapeutic relationship that allowed for progress with expressive, musical and attention-based goals.

The five themes described in the findings from the analysis of the clinical data (see 4.2) are all goal-oriented processes that are demonstrated in my work with Hayden. The formation of an authentic and therapeutic relationship was central to our music therapy, supporting his development through a largely client-centred approach. I embraced Hayden's strengths and contributions in a client-centred way to develop goals that were meaningful for him and his family. This was initiated by the referral and assessment process and supported by ongoing observation and documentation, but ultimately sculpted and refined through collaboration with Hayden and his family. Through the nurturing of the therapeutic relationship and by working in a clientcentred way, we developed goals together that engaged his interests as well as my perception of his needs in order to help him develop skills that could be then generalised into other environments. 


\section{Discussion}

\subsection{Goal-Oriented Processes}

Before this research had begun, I pondered whether goal-oriented processes was a term that could be considered an approach to music therapy - 'to be a goal-oriented music therapist' (as opposed to behaviourist, music-centred, etc.). Instead, I found that it was less of an approach and more a particular method or strategy that a music therapist might use in music therapy, and that our philosophy or approach influences what those goal-oriented processes are. In other words, the actual things we do to form and work towards a goal can be called a goal-oriented process, whilst our approach affects how we form and work towards a goal. Our approach defines what the goal-oriented processes are. Although I felt aware of my largely client-centred philosophical approach, I was surprised at the extensive influence of the therapeutic relationship that emerged in my analysis. I had not expected my philosophical approach to impact the way goals were realised as strongly, instead thinking that the goals would remain the same no matter the philosophical approach, and its influence would be limited to how I worked towards those goals.

Upon reflecting on the findings in relation to current literature, I also noticed links to models other than a client-centred approach in the case of Hayden, described in the vignette. Hanser's (2015) description of Cognitive Behavior Therapy details "a strong therapeutic alliance with active participation by clients and collaboration between therapists and clients", "goal- and problem-oriented focus", "an educative philosophy, with the ultimate aim of teaching clients to be their own therapists", before suggesting that sessions "might start with a mood check, then move toward problem identification and goal setting". These links felt surprisingly familiar in their similarity to some of the codes and were significant findings to Hayden's case. Although these connections were largely only identified in the one case, this demonstrates a flexibility of approaches in order to meet the needs of the client.

\subsection{Contexts}

It is important to emphasise the contextual nature of the goal-oriented processes I used, recognising the environment, the client population, and my own background as 
contributing factors to my approach. The contextual nature of goal-oriented processes means that it is impossible to foresee what the processes will be before we are working with the client. This context-bound, ecological way of thinking is current in music therapy literature, discussed by: Ansdell (2014) who links it to Christopher Small's (1998) concept of 'Musicking' by encouraging therapists to view experiences amongst the complex interactions with their environments; and Rolvsjord \& Stige (2015) who call for greater acknowledgement of context in music therapy literature. Upon reflecting on the first stage of data analysis, the literature often described how goals are used in music therapy, however only in one (Molyneux et al., 2011) was the context clearly defined in detail. It is evident that the context had a significant influence on how goaloriented processes were used in my case, and hence I felt it necessary to detail the circumstances of my experiences in order to contextualise them for the reader.

Swamy (2014) emphasises this call for awareness with a focus on cultural contexts, encouraging music therapists to be aware of contexts through reflective ethnographicstyled research. Kim \& Whitehead-Pleaux (2015) extend this to encourage adaptive practice by stating "If the client's values and belief systems differ from our own, then therapy treatment plans-including goals, assessments, and evaluations-should all be revised according to the individual's cultural values" (p. 54). By actively working to increase my awareness of the many contexts involved in every case I am able to adapt my approaches, and in doing so I am able to work closely with the client in order to realise meaningful goals.

\subsection{Documentation}

The style of documentation used in my clinical data was descriptive and sometimes written in a narrative-style to convey the sense of development. I recognise that it was appropriate for the facility at the time and that if I were to work at a different facility or was required to provide a different style of documentation for external funders (e.g. a government body or educational facility), then my approach and style of documentation, objectiveness of goals etc. may change to fit. However, following on from the theme of context, it is interesting to note that current thinking in special education in New Zealand is moving away from standardised assessment processes. Educators are instead using narrative assessment as a client-centred, strengths-based approach whereby individuals are empowered within their own treatment plan to work 
towards meaningful goals (Ministry of Education, 2009). This rich, descriptive, and collaborative form of observation and documentation is pertinent to my findings, in which I found that similar approaches helped to identify clients' strengths and realise meaningful goals that could be worked towards resourcefully. The shared concept of looking at how we work with an individual from a different perspective is especially valuable in both contexts as it encourages individualised approaches for the clients' benefit. It also addresses my finding that the consideration of emotional states on clients' achievements allowed development to be recognised in multiple contexts. Narrative assessment has been demonstrated as applicable to music therapy, benefiting clients and their families, as well as working to close the gap between individualised humanistic approaches and standardised approaches to assessment (Jourdan, 2010). Clients are empowered to adopt a stronger and more influential role in their own treatment goals and strategies.

\subsection{Autism Spectrum Disorder and Goal-Oriented Processes}

As a spectrum disorder, clients who have been diagnosed with ASD are diverse in their strengths as well as their needs, demanding a wide range of individualised approaches. The flexible client-centred nature of my approaches allowed for strengths-based practice that could be individualised to each client. This was especially important for clients with ASD because of their tendency to fail to thrive educationally. By forming goals that were meaningful and useful (and more importantly the development towards those goals) they were able to experience positive progression that put them in a good place for further development. The SCERTS model has also been shown to help music therapists to form and follow clearly laid out goals for young people with ASD using a structured approach (Ayson, 2011). Although the facility I worked at valued more flexible holistic approach, this structured approach would be valuable in settings that involve multi-disciplinary treatments or require more generalisable results.

One of the ways in which I was able to create and work towards meaningful goals was through the formation and nurturing of therapeutic relationships. However, as presented in the literature review, the DSM-V (American Psychiatric Association, 2013) states that individuals with ASD often have trouble developing, maintaining and understanding relationships. Although these initially appeared to be conflicting statements, on reflection it became clear that the less confrontational nature of music 
allowed for the clients to engage in therapeutic relationships that may not have been possible through other forms of therapy.

\subsection{Limitations and Recommendations for Future Research}

Some limitations and recommendations have already been made, however it is important to acknowledge the small data set that was analysed in this research. Working with a larger population would provide a greater sense of how I work within a wider range of contexts. Investigation into the same subject with clients who have other diagnoses may yield different results. The extensive nature of goal-oriented thinking throughout my clinical data meant that the findings at times read as a description of how I worked generally, causing a breadth of inquiry that felt problematic. Although it provided an overview of how I worked with goal-oriented processes throughout the therapy process, it would be beneficial for future research to focus on a specific part of the music therapy process (such as the assessment period) and analyse goal-oriented processes within that in more depth. However, I do still feel that the research provided a good overview of how goal-oriented processes are used throughout my music therapy practice. I now have a greater understanding of the different stages of work with goals and realise that they are a very useful lens for reflecting on how I am able to support clients. It is important to acknowledge that the qualitative and contextual nature of this research means that findings cannot be generalised, however it is hoped that the concepts may provoke reflection for other music therapists on their practice in the highlighted areas. 


\section{Conclusion}

This research aimed to investigate how I was able to support young people with autism spectrum disorder through my use of goal-oriented processes. Young people with autism spectrum disorder respond to music therapy in a wide variety of ways that are unique to themselves, the environment, the therapist, and other contextual elements. My approaches to the use of goals in music therapy developed in alignment with a humanistic philosophy, which lead me to practice predominantly as a client-centred music therapist. This was influenced by my personal contexts and was specific to the particular facility and the population that I was working with. I found that I valued the therapeutic relationship as a platform on which strengths could be identified, individualised goals could be formed, and development that was meaningful to the clients and their caregivers could be made. This was valued throughout the therapeutic process, including during endings of therapeutic episodes when the focus of sessions became bringing closure to the therapeutic relationship. An emphasis on therapeutic relationships and collaboration with clients and their caregivers throughout the therapy process influenced the ways in which I used goal-oriented processes, meaning I was able to support the clients by realising goals that were meaningful for them. I also collaborated with clients' caregivers to help clients to reach their goals, both actively and through their observations. The referral, assessment and review processes supported regular collaboration by providing a framework in which goals could be regularly reflected upon and assessed for suitability. This was assisted by detailed observation and descriptive documentation that clearly illustrated the clients' individual development for everyone involved in the clients' treatment. Goal-oriented processes also support music therapy to be more resolution-driven and in doing so support it as an evidence-based practice. Although the qualitative nature of this research means that it is not generalisable beyond the contexts in which it takes place, it provides insight into what goal-oriented processes can involve, and encourages music therapists and other professionals alike to reflect and share how they are able to support clients through the use of goal-oriented processes. 


\section{References}

Abrams, B. (2015). Humanistic approaches. In B. L. Wheeler (Ed.), Music therapy handbook (pp. 148-160). New York, NY: Guilford Publications.

Aigen, K. (2005a). Music-centered music therapy. Gilsum, NH: Barcelona Publishers.

Aigen, K. (2005b). Naturalistic inquiry. In B. L. Wheeler (Ed.), Music therapy research (2nd Ed., pp. 352-364). Gilsum, NH: Barcelona Publishers.

American Music Therapy Association. (2013). AMTA standards of practice. Retrieved from http://www.musictherapy.org/about/standards

American Psychiatric Association. (2013). Diagnostic and statistical manual of mental disorders (5th ed.). Arlington, VA: American Psychiatric Publishing.

Ansdell, G. (2014). How music helps in music therapy and everyday life. Farnham, England: Ashgate.

Australian Music Therapy Association. (2014). Code of ethics. Retrieved from http://www.austmta.org.au/system/files/Code of Ethics 2014.pdf

Ayson, C. (2011). The use of music therapy to support the SCERTS model objectives for a three year old boy with autism spectrum disorder in New Zealand. New Zealand Journal of Music Therapy, 9, 7-31.

Baxter, H. T., Berghofer, J. A., MacEwan, L., Nelson, J., Peters, K., \& Roberts, P. (2007). The individualized music therapy assessment profile: IMTAP. London, England: Jessica Kingsley Publishers.

Berger, D. S. (2002). Music therapy, sensory integration and the autistic child. London, England: Jessica Kingsley Publishers.

Bowens, A., Scheib, E., \& Larking, P. (2011). Brief report: Update on the effectiveness of music therapy for autistic spectrum disorders, cerebral palsy and traumatic brain injury. New Zealand.

Braun, V., \& Clarke, V. (2006). Using thematic analysis in psychology. Qualitative Research in Psychology, 3(2), 77-101.

Bretherton, I. (1992). The origins of attachment theory: John Bowlby and Mary Ainsworth. Developmental Psychology, 28(5), 759.

Brunk, B. K. (2004). Music therapy: Another path to learning and communication for children on the autism spectrum. Arlington, TX: Future Horizons.

Bruscia, K. E. (1987). Improvisational models of music therapy. Springfield, IL: Charles Thomas.

Bruscia, K. E. (1998). Defining music therapy (2nd ed.). Gilsum, NH: Barcelona Publishers. 
Carpente, J. A., \& LaGasse, A. B. (2015). Music therapy for children with autism spectrum disorder. In B. L. Wheeler (Ed.), Music therapy handbook (pp. 290-301). New York, NY: Guilford Publications.

Cohen, G., \& Gericke, O. L. (1972). Music therapy assessment: prime requisite for determining patient objectives. Journal of Music Therapy, 9(4), 161-189.

Dileo, C., \& Bradt, J. (2007). Music therapy: Applications to stress management. In P. M. Lehrer, R. L. Woolfolk, \& W. E. Sime (Eds.), Principles and practice of stress management (3rd ed.). New York, NY: Guilford Press.

Dimitriadis, T., \& Smeijsters, H. (2011). Autistic spectrum disorder and music therapy: Theory underpinning practice. Nordic Journal of Music Therapy, 20(2), 108-122.

Edwards, J. (1999). Considering the paradigmatic frame: Social science research approaches relevant to research in music therapy. The Arts in Psychotherapy, 26(2), 73-80.

Geretsegger, M., Elefant, C., Mossler, K. A., \& Gold, C. (2014). Music therapy for people with autism spectrum disorder. Cochrane Database of Systematic Reviews, 2014(6), Cd004381.

Gold, C. (2011). Special section: Music therapy for people with autistic spectrum disorder. Nordic Journal of Music Therapy, 20(2), 105-107.

Hanser, S. (2015). Cognitive-behavioral approaches. In B. L. Wheeler (Ed.), Music therapy handbook (pp. 161-171). New York, NY: Guilford Publications.

Heaton, J. (2004). Reworking qualitative data. London, England: SAGE Publications.

Jourdan, N. (2010). Narrative assessment and music therapy: The use of the Ministry of Education's project, assessment for learners with special education needs, to provide prompt feedback on music therapy sessions. Retrieved from http://www.musictherapy.org.nz/wp-content/uploads/downloads/2011/08/2010MTHNZ-Notes-from-Conference.pdf

Kim, S., \& Whitehead-Pleaux, A. (2015). Music therapy and cultural diversity. In B. L. Wheeler (Ed.), Music therapy handbook (pp. 51-63). New York, NY: Guilford Publications.

Lord, C., \& Bishop, S. L. (2010). Autism spectrum disorders: Diagnosis, prevalence, and services for children and families. Social Policy Report, 24(2), 1-27.

Magee, W. (1999). Music therapy within brain Injury rehabilitation: To what extent is our clinical practice influenced by the search for outcomes? Music Therapy Perspectives, 17(1), 20-26.

McCarney, R., Warner, J., Iliffe, S., van Haselen, R., Griffin, M., \& Fisher, P. (2007). The Hawthorne Effect: a randomised, controlled trial. BMC Medical Research Methodology, 7,30 . 
McFerran, K. S., \& Shoemark, H. (2013). How musical engagement promotes well-being in education contexts: The case of a young man with profound and multiple disabilities. International Journal of Qualitative Studies on Health and Well-Being, 8.

Ministry of Education. (2009). Narrative assessment: A guide for teachers. Wellington, New Zealand: Learning Media.

Molyneux, C., Willis, M., Talmage, A., Scoones, R., Travaglia, R., Gang, N.-H., \& PiggotIrvine, E. (2011). Collaborative goal setting and reviewing in music therapy for children with special needs: An action research project to improve practice and measure efficacy. Retrieved from http://hdl.handle.net/10652/2114

Music Therapy New Zealand. (2012). Code of ethics for the practice of music therapy in New Zealand. Retrieved from www.musictherapy.org.nz/documents/Code-of-Ethics-2012.pdf

New Zealand Education Gazette, T. K. (2009). Family connections. New Zealand Education Gazette, Tukutuku Kōrero, 88(5).

Nordoff, P., \& Robbins, C. (1977). Creative music therapy: Individualized treatment for the handicapped child. New York, NY: John Day.

Pavlicevic, M., \& Ansdell, G. (2004). Community music therapy. London, England: Jessica Kingsley Publishers.

Prizant, B. M., Wetherby, A. M., Rubin, E., \& Laurent, A. C. (2003). The SCERTS model. Infants \& Young Children, 16(4), 296-316.

Ricciarelli, A. (2003). The guitar in palliative music therapy for cancer patients. Music Therapy Today, 4(2).

Rickson, D. J. (2006). Instructional and improvisational models of music therapy with adolescents who have attention deficit hyperactivity disorder (ADHD): A comparison of the effects on motor impulsivity. Journal of Music Therapy, 43(1), 39-62.

Rogers, C. R. (1951). Client-centered therapy: Its current practice, implications, and theory. London, England: Constable.

Rogers, C. R. (1995). On becoming a person: A therapist's view of psychotherapy. Boston, MA: Houghton Mifflin.

Rolvsjord, R., \& Stige, B. (2015). Concepts of context in music therapy. Nordic Journal of Music Therapy, 24(1), 44-66.

Saldaña, J. (2013). The coding manual for qualitative researchers. (2nd ed.). Los Angeles, CA: SAGE Publications.

Sandin, S., Lichtenstein, P., Kuja-Halkola, R., Larsson, H., CM, H., \& Reichenberg, A. (2014). The familial risk of autism. JAMA, 311(17), 1770-1777.

Slaughter, V. (2015). Autism. Magill's Medical Guide (Online Edition). Pasadena, CA: 
Salem Press.

Small, C. (1998). Musicking: The meanings of performing and listening. Hanover, Germany: University Press of New England.

Swamy, S. (2014). Music therapy in the global age: Three keys to successful culturally centred practice. New Zealand Journal of Music Therapy, (12), 34-57.

Thaut, M. H. (1984). A music therapy treatment model for autistic children. Music Therapy Perspectives, 1(4), 7-13.

Thaut, M. H., \& Hoemberg, V. (2014). Handbook of neurologic music therapy. New York, NY: Oxford University Press.

Victoria University of Wellington. (2015). Human ethics policy. Retrieved from http://www.victoria.ac.nz/documents/policy/research-policy/human-ethics-policy.pdf

Walworth, D. D. (2007). The use of music therapy within the SCERTS model for children with autism spectrum disorder. Journal of Music Therapy, 44(1), 2-22.

Wheeler, B. L., \& Kenny, C. (2005). Principles of qualitative research. In B. L. Wheeler (Ed.), Music therapy research (2nd Ed., pp. 59-71). Gilsum, NH: Barcelona Publishers.

Wheeler, B. L., Shultis, C. L., \& Polen, D. (2005). Clinical training guide for the student music therapist. Gilsum, NH: Barcelona Publishers.

Wigram, T., \& Gold, C. (2006). Music therapy in the assessment and treatment of autistic spectrum disorder: Clinical application and research evidence. Child: Care, Health and Development, 32(5), 535-542.

Wigram, T., Pedersen, I. N., \& Bonde, L. O. (2002). A comprehensive guide to music therapy: Theory, clinical practice, research and training. London, England: Jessica Kingsley Publishers. 


\section{Appendices}

\subsection{Glossary of Terms}

ADHD: Attention Deficit Hyperactivity Disorder

ASD: Autism Spectrum Disorder

GAS: Goal Attainment Scaling

GDD: Global Developmental Delay

IEP: Individual Education Plan

IMTAP: Individualized Music Therapy Assessment Profile

RMTh: Registered Music Therapist (New Zealand)

SCERTS: Social Communication, Emotional Regulation and Transactional Support Model Caregiver: refers to the parent or primary caregiver of the client

Client: refers to the individual receiving music therapy treatment

Facility: refers to the location or the organisation in which the music therapy takes place 


\subsection{Example of Initial Coding}

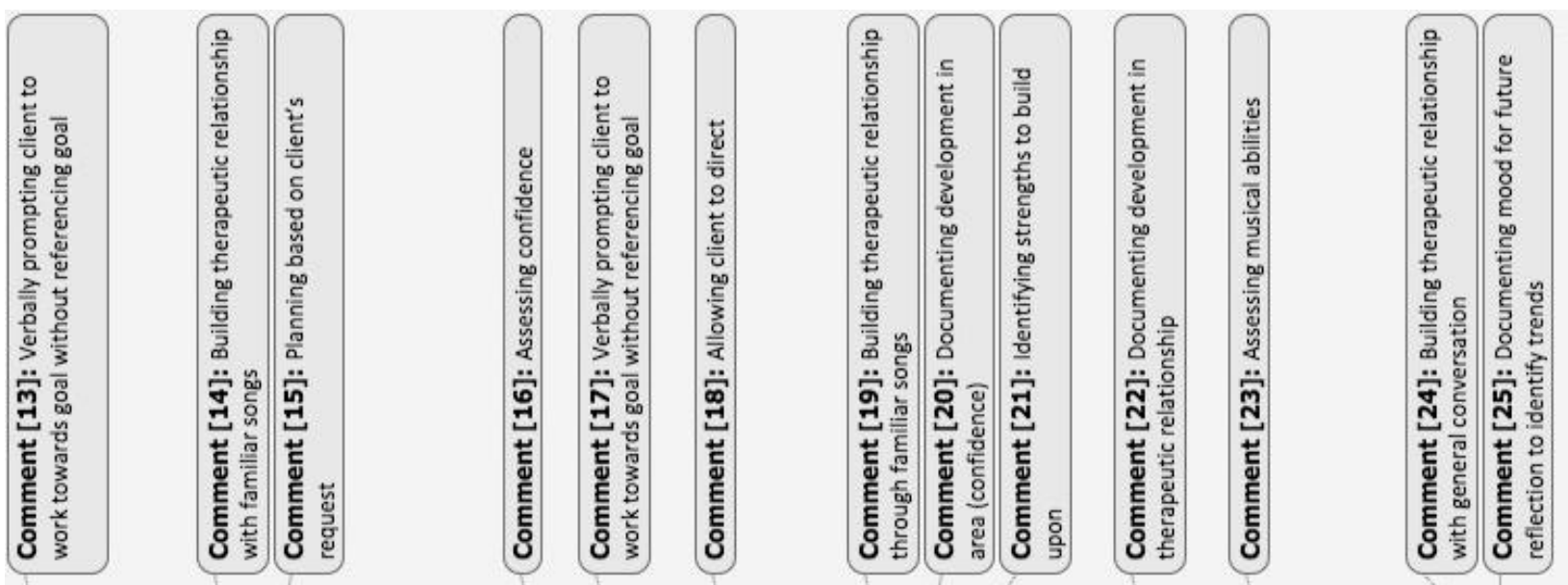

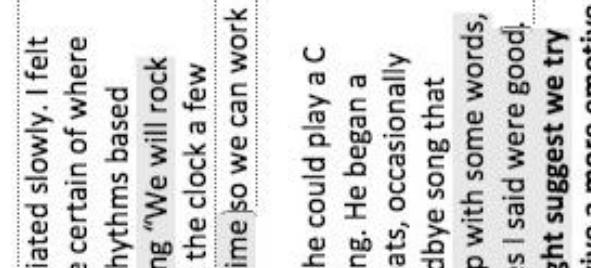

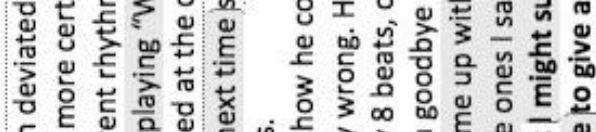

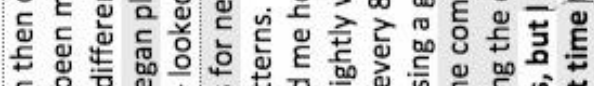

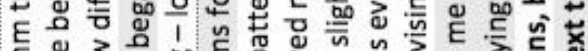
E

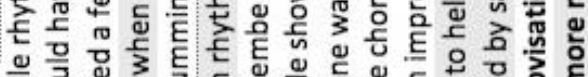
ब음을 흔

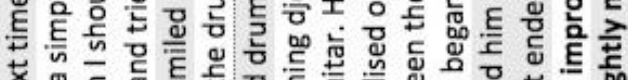

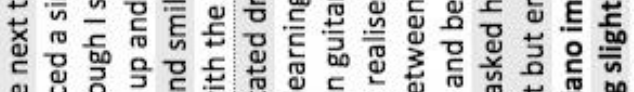

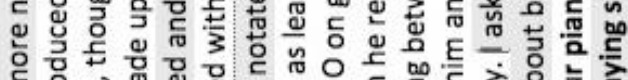

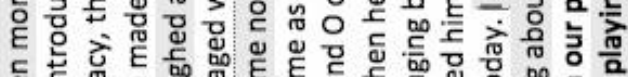

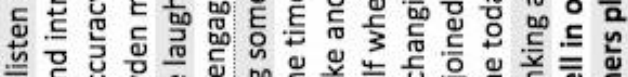
记

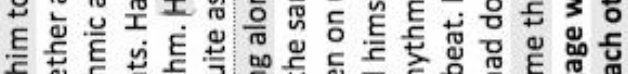

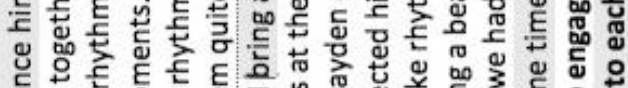
낭

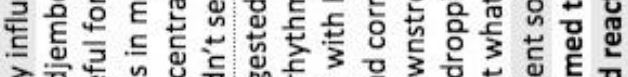

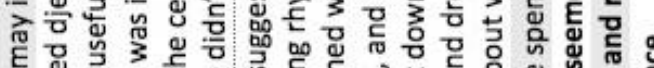

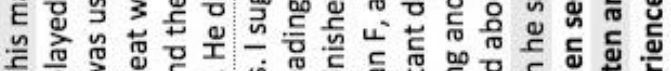

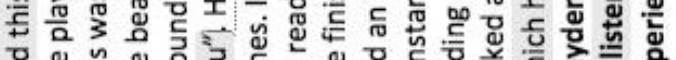

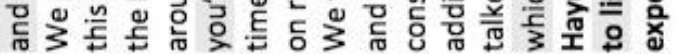

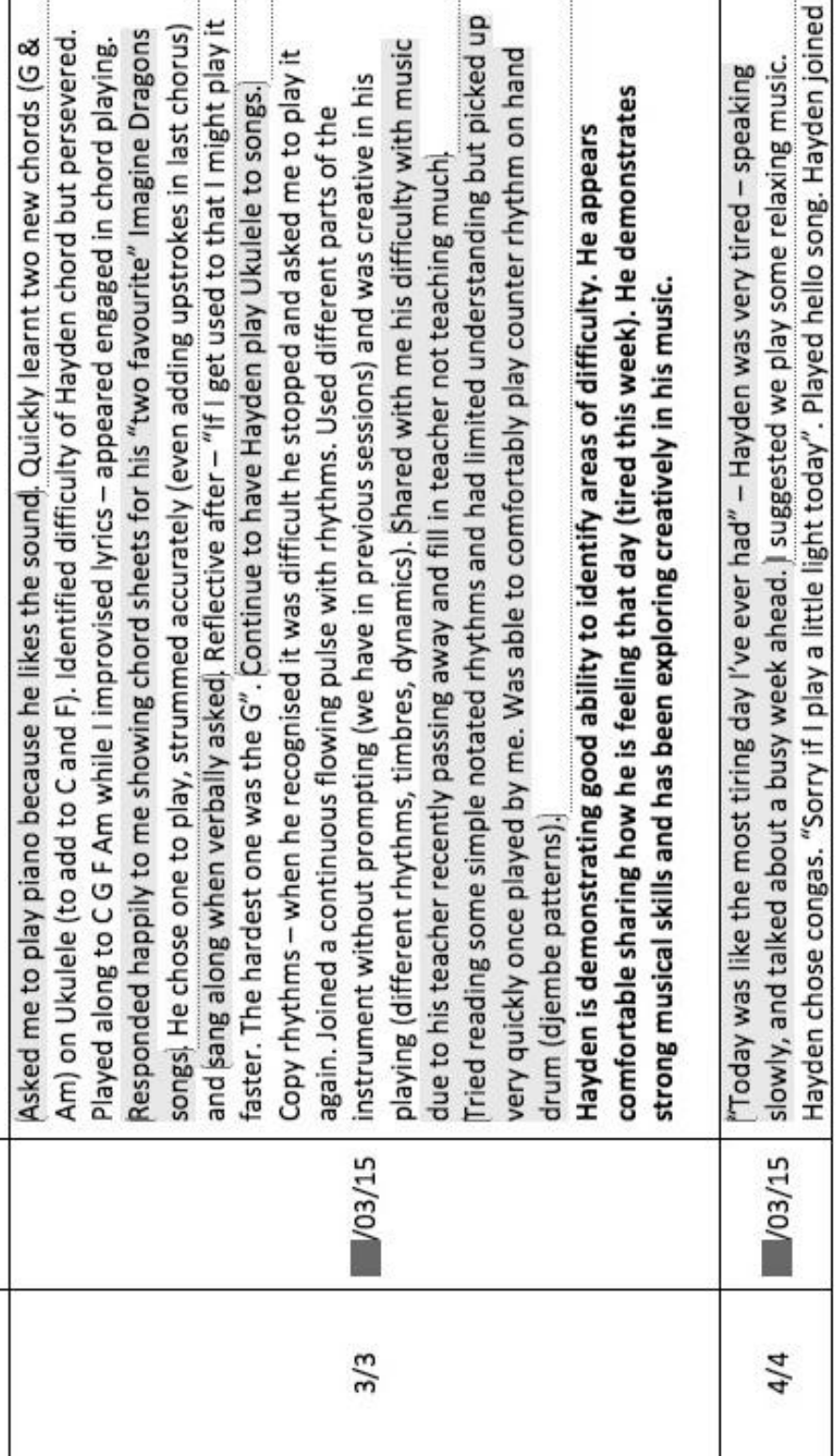




\subsection{Example of Thematic Analysis}

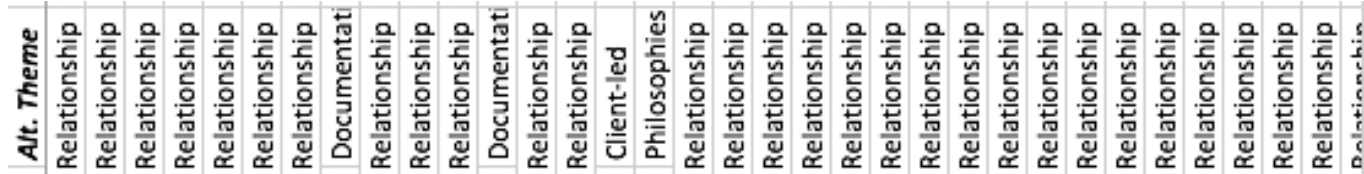

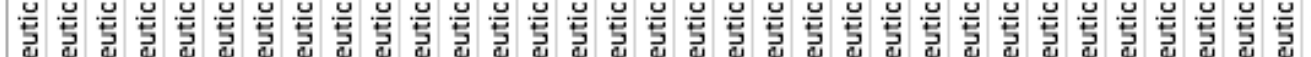

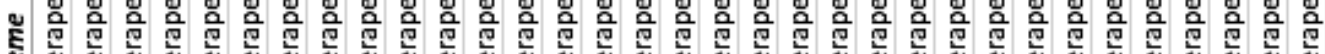
है F

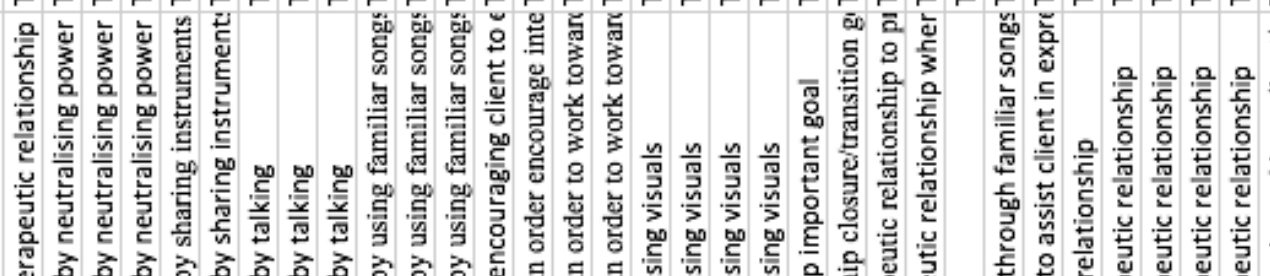

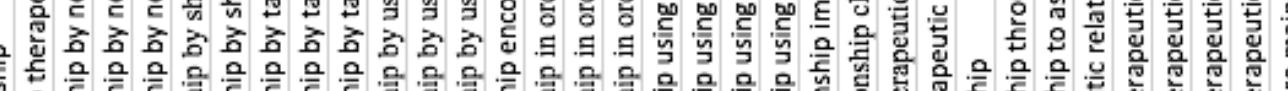

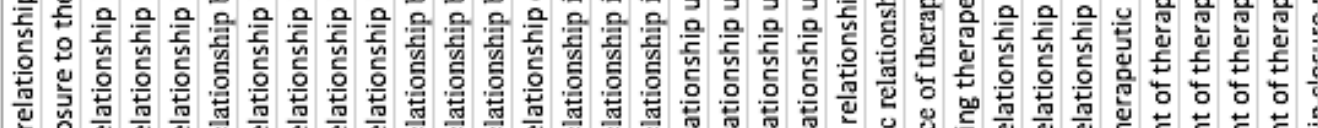

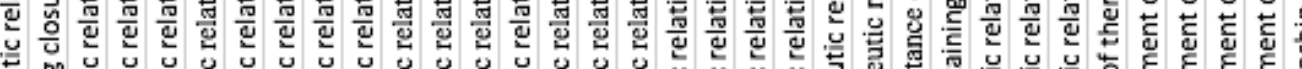

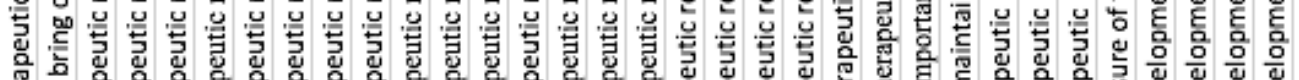

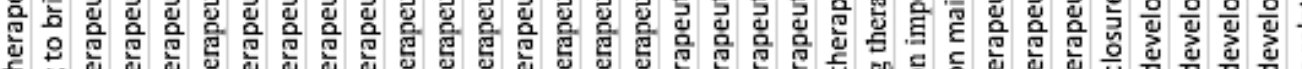

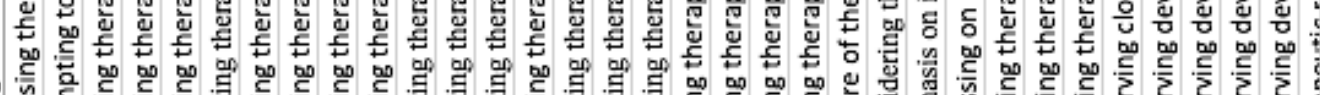

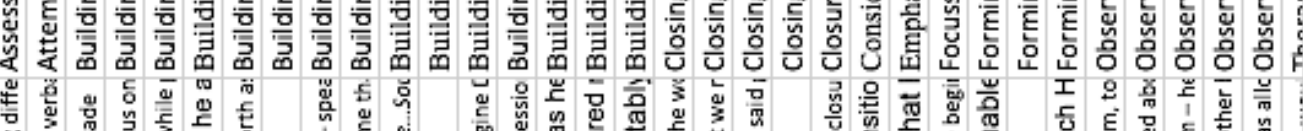

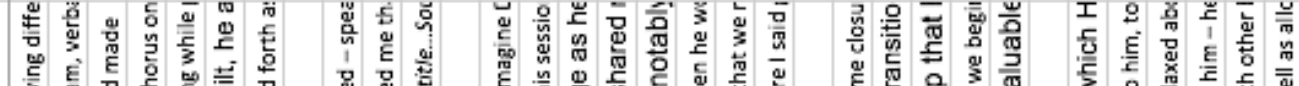

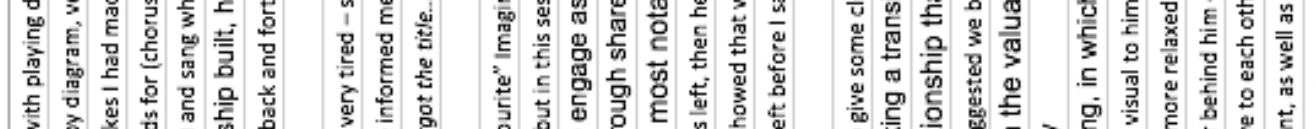

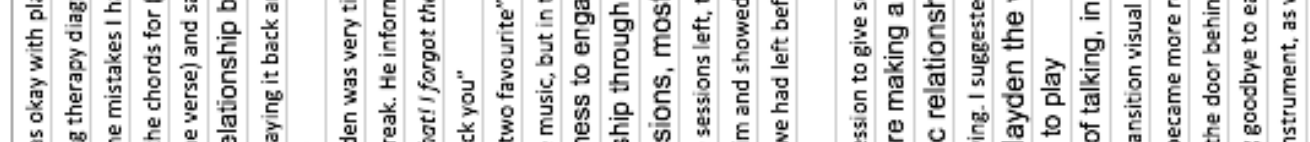

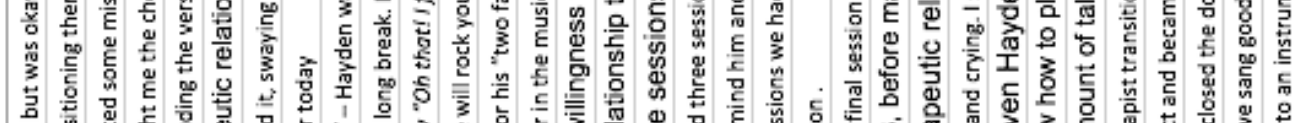

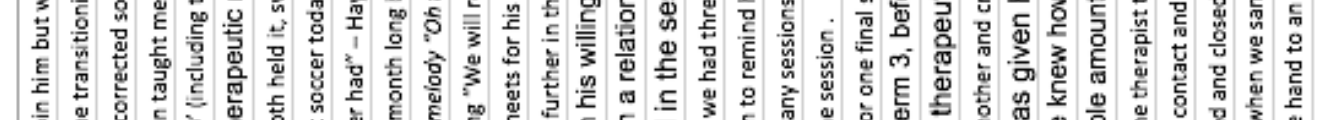

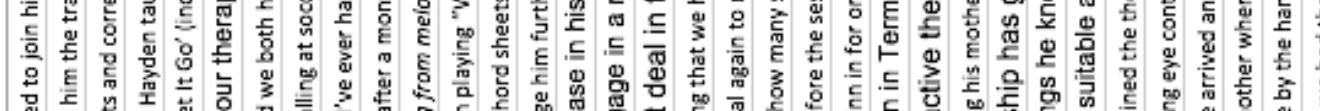

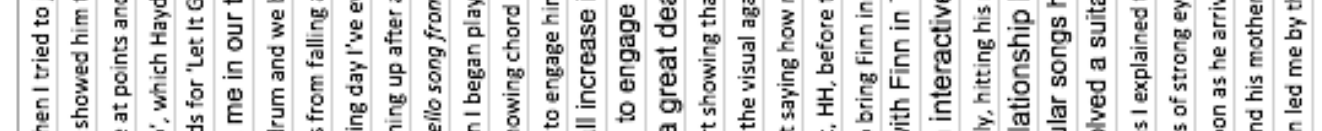

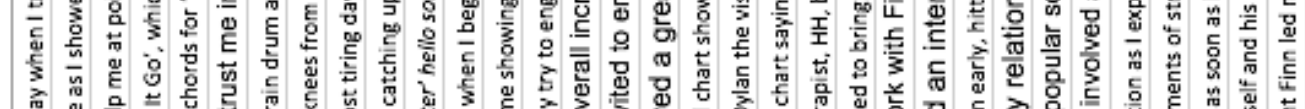

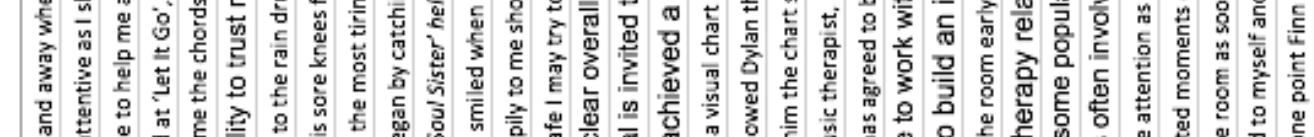

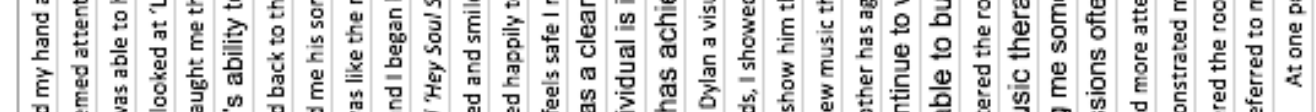

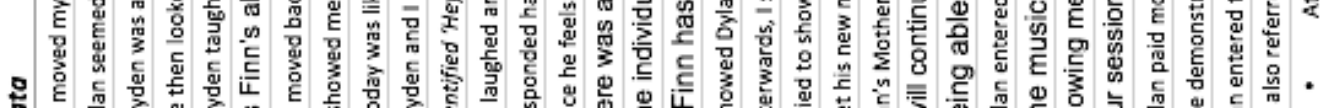

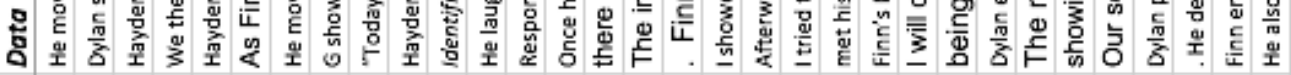

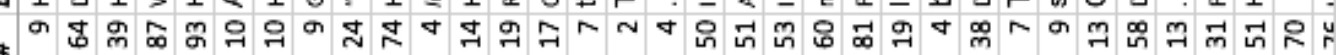

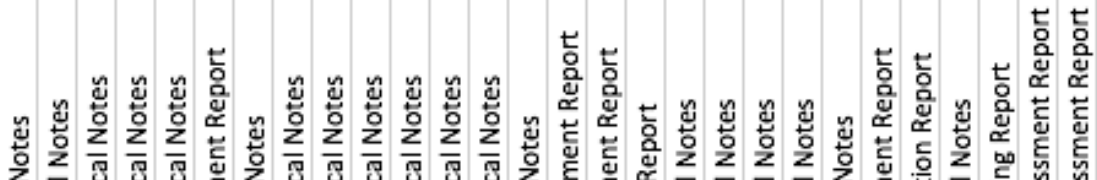

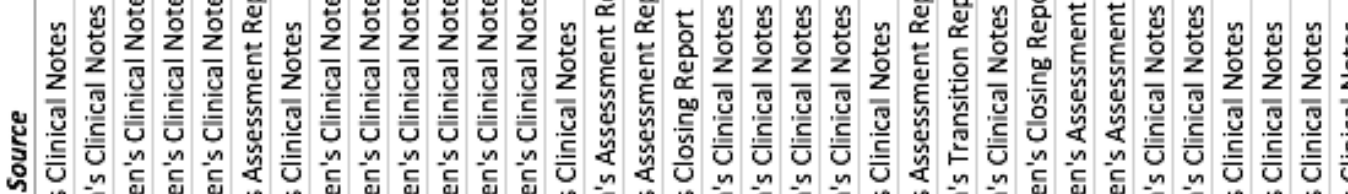
h

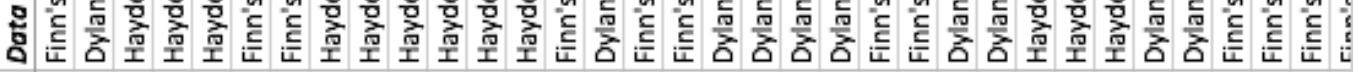

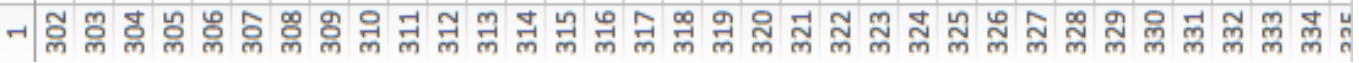




\subsection{Example of Goal Monitoring Sheet}

\section{Monitoring sheet for music therapy goals and focus areas}

Date: $\mathrm{X}$

Name: Hayden

DOB: $X$

Music Therapist: Olly Lowery

\begin{tabular}{|l|l|l|}
\hline \multicolumn{1}{|c|}{ Focus Area } & \multicolumn{1}{|c|}{ Short-term Goal } & \multicolumn{1}{c|}{ Strategies } \\
\hline $\begin{array}{l}\text { Creative Self- } \\
\text { expression }\end{array}$ & $\bullet \begin{array}{l}\text { Continue to explore a wide range of } \\
\text { instruments } \\
\text { Recognise and utilise the musical space as a } \\
\text { means for expression }\end{array}$ & $\begin{array}{l}\text { - Song writing } \\
\text { Free improvisation } \\
\text { Thematic } \\
\text { improvisation } \\
\text { Lyric analysis }\end{array}$ \\
\hline
\end{tabular}

Evidence (This may include a rating system related to qualitative or quantitative outcomes, a yes/no answer or other measure.)

\begin{tabular}{|c|c|c|}
\hline DATE & Progress & COMMENTS \\
\hline $21 / 07 / 15$ & Yes & $\begin{array}{l}\text { Began songwriting - Hayden came up with chords, how long each should be } \\
\text { played, and altered them to fit. He then came up with a title and theme - } \\
\text { 'Victory' (may or may not relate to achieving music performance with } \\
\text { excellence?). }\end{array}$ \\
\hline $28 / 07 / 15$ & Yes & $\begin{array}{l}\text { Songwriting - expressive lyrics written and clear directions given about how he } \\
\text { wanted the song to sound in structure and harmony (detailed in session notes). }\end{array}$ \\
\hline 04/08/15 & Yes & Started new song (theme of romance) then combined with old song to finish. \\
\hline $11 / 08 / 15$ & Yes & $\begin{array}{l}\text { Initiated lyrical analysis of 'Let It Go' without prompting. Was open to sharing his } \\
\text { song he had written in previous weeks. }\end{array}$ \\
\hline $25 / 08 / 15$ & Yes & $\begin{array}{l}\text { Sang familiar songs initially shyly, but built in confidence. Experienced the electric } \\
\text { bass guitar and used the guitar more than ukulele. Compared and gave } \\
\text { preference for the sound when songs are played on piano over ukulele and } \\
\text { guitar. }\end{array}$ \\
\hline $01 / 09 / 15$ & Yes & $\begin{array}{l}\text { Hayden suggested recording his song he had written with me, and asked how we } \\
\text { might do that. We also improvised on the theme of finishing music therapy (MT's } \\
\text { idea) and Hayden described afterwards about purposefully playing both happy } \\
\text { and sad sounds on the piano. }\end{array}$ \\
\hline 08/09/15 & Yes & $\begin{array}{l}\text { Hayden planned out how we would record his song and put it on a USB for him } \\
\text { before he finishes. He also initiated lyric analysis on a new song he had asked me } \\
\text { to learn ( } 7 \text { Lions - One More Time), and related this to his own life, bringing up } \\
\text { themes to do with X. }\end{array}$ \\
\hline $15 / 09 / 15$ & Yes & $\begin{array}{l}\text { We recorded G.'s song he had written, and he chose the instrumentation, tempo, } \\
\text { dynamics, and made some amendments to the lyrics/structure. Hayden seemed } \\
\text { proud of his recorded, commenting that the second take "seemed like it might be } \\
\text { the one". There was some brief lyric analysis of his own song as well as 'One } \\
\text { More Time' - } 7 \text { Lions. }\end{array}$ \\
\hline $22 / 09 / 15$ & Yes & $\begin{array}{l}\text { Hayden discussed his musical future and how once he practices enough, he might } \\
\text { record some covers and put them on YouTube. }\end{array}$ \\
\hline
\end{tabular}




\subsection{Letter Seeking Permission to Perform Research at Facility}

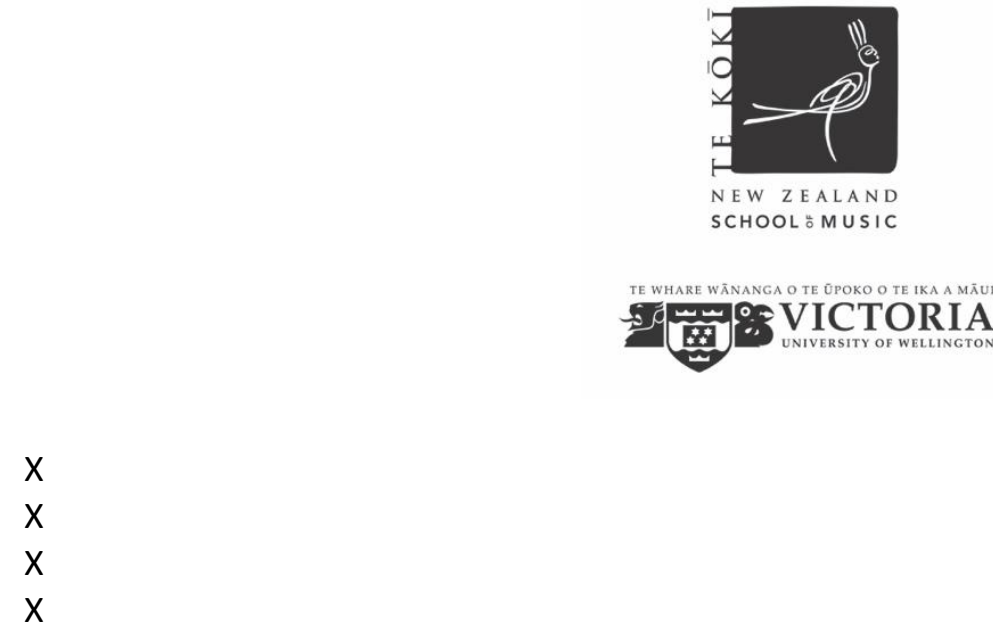

Olly Lowery

Te Kōkī New Zealand School of Music

Victoria University of Wellington

PO Box 600

Wellington 6140

Friday $14^{\text {th }}$ August 2015

Dear X (and whom else it may concern at X),

I am in my second year of Masters of Music Therapy degree, and as part of the programme I am required to conduct research relating to the clinical work by using secondary review of data. I have titled my research question "How does a student music therapist utilise goal-oriented processes to support young people with special needs". This project has been reviewed and approved by the NZSM Postgraduate Committee. I have attached a research proposal for further information about my study.

I would like to ask you for a written permission for the research to take place at X. Please feel free to discuss with me about my research and/or giving permission to conduct research. If you feel you have obtained sufficient information about this research and happy to give permission, please could you send me an email by $21^{\text {st }}$ August to confirm, as I will need your statement to proceed with my research.

Please contact me or my research supervisor Sarah Hoskyns if you have any concerns or questions relating to this research.

Yours sincerely,

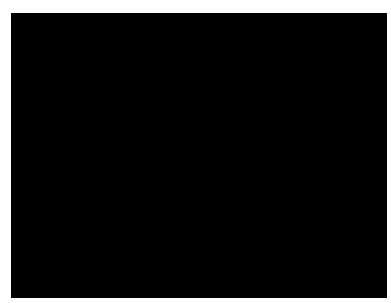

Olly Lowery

Attachment: Research Proposal 


\subsection{Example Information Sheet for Clients}
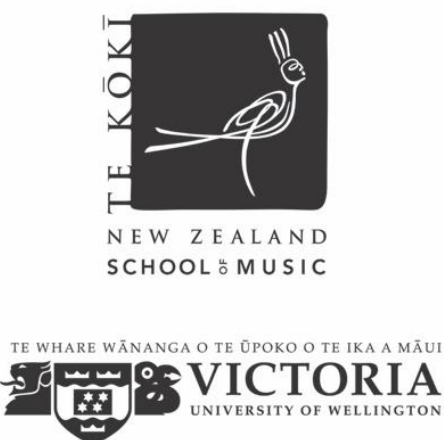

\section{How does a student music therapist utilise goal-oriented processes to support young people with autism spectrum disorder? - Olly Lowery}

\section{INFORMATION SHEET}

\section{My Research}

As you know, I have been working as a student music therapist at $\mathrm{X}$ this year for university. I am doing a 'Master of Music Therapy' degree at the New Zealand School of Music. For my degree I am also researching 'goal-oriented processes', which I hope will help me to understand more about goals in music therapy.

First I am going to look at other peoples research to see how they use goals. Then I am going to look at my notes that I've written over the year at X to see how I have used goals. This reflection can help me to be a better music therapist. For my research I also have to write a story about one piece of music therapy I've done, which will be called my 'vignette'. I am writing to you because I would like to talk about our music therapy for that story.

\section{Why?}

The reason I am writing a story in my research is because it shows the people who might read my research how I have actually used goals in real life. If you did want me to write about our music therapy then I would use a made-up name for you, so that it would hard for people to recognise who the story is about. X. You wouldn't have to do anything for my research because I will just be writing about what we have already done. The focus of the story would be on what I did, not what you did.

\section{After the research is finished}

Once I have finished my research I would tell you what I have written about, as well as showing you the story I'd have written. My research will be available for people to look at through the university library (New Zealand School of Music). I will also show my research in private to my examiners, and might talk about it with other music therapists at X. There is also a possibility that later on I might decide to put my research into a professional journal, where other professionals share their research. 


\section{Your Rights}

You do not have to say yes to having our story included in my research because I can ask other people who I have worked with if you say no. If you decide that you do want it to be used, you can:

- ask any questions about the research at any time until it is completed;

- change your mind before October $30^{\text {th }}, 2015$ if you decide you don't want me to write about our story;

- see the research when it is finished.

If you have any questions then you can ask me or my supervisor, whose emails and phone numbers are shown below - we don't mind!

Researcher: Olly Lowery

Email: loweryoliv@myvuw.ac.nz

Contact number: $\mathrm{X}$

Supervisor: Sarah Hoskyns (Associate Professor, Director of Master of Music Therapy Programme, Te Kōkī, New Zealand School of Music)

Email: sarah.hoskyns@nzsm.ac.nz

Contact number: (0064) 04-463-5233 x 35807

\section{Ethical Approval}

This project has been reviewed and approved by the New Zealand School of Music Postgraduate committee. The VUW Human Ethics Committee has given generic approval for music therapy students to conduct studies of this type. The music therapy projects have been judged to be low risk and, consequently, are not separately reviewed by any Human Ethics Committees. The supervisor named below is responsible for the ethical conduct of this research. If you have any concerns about the conduct of this research, please contact the supervisor or, if you wish to raise an issue with someone other than the student or supervisor, please contact the Victoria University of Wellington Human Ethics Convenor AProf Susan Corbett, email susan.corbett@vuw.ac.nz, telephone +64-4-463 5480) 


\subsection{Example Consent Form for Clients}
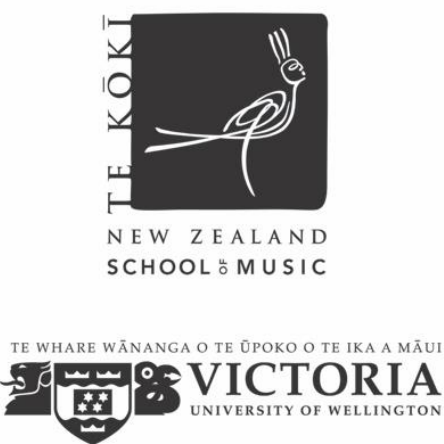

How does a student music therapist utilise goal-oriented processes to support young people with autism spectrum disorder? - Olly Lowery

\section{CONSENT FORM - INDIVIDUAL}

I have read the Information Sheet and it makes sense. I was able to ask any questions and the answers made sense, and I know that I can ask more questions at any time. I know that I can change my mind about saying yes up until October $30^{\text {th }}, 2015$.

I agree/do not agree to our story being used for Olly's research, as talked about in the Information Sheet. (Circle One)

Signature:

Date:

Full Name - printed 


\subsection{Example Consent Form for Caregivers}
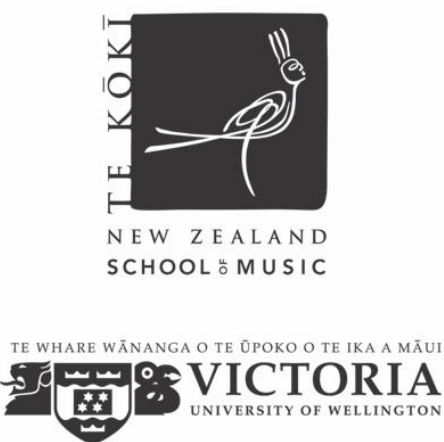

How does a student music therapist utilise goal-oriented processes to support young people with autism spectrum disorder? - Olly Lowery

\section{PARENT CONSENT FORM - INDIVIDUAL}

I have read the Information Sheet and have had the details of the study explained to me. My questions have been answered to my satisfaction, and I understand that I may ask further questions at any time. I understand I can withdraw my information from the research up till the end of the data analysis (October $30^{\text {th }}, 2015$ )

I agree/do not agree to my child's clinical notes being used for reflection and analysis for research purposes, under the conditions set out in the Information Sheet.

Signature:

Date:

Full Name - printed 